\title{
WILEY-VCH
}

DOI: $10.1002 /$ ((please add manuscript number))

Article type: Full Paper

\section{Molybdenum Dioxide in Carbon Nanoreactors as a Catalytic Nanosponge for the Efficient Desulphurisation of Liquid Fuels}

Maxwell A. Astle, Graham A. Rance, Hannah J. Loughlin, Thomas D. Peters, and Andrei N. Khlobystov*

M. A. Astle ${ }^{a}$, Dr. G. A. Rance ${ }^{a, b}$, H. J. Loughlin ${ }^{a}$, T. D. Peters ${ }^{a}$, Prof. A. N. Khlobystov ${ }^{a, b}$

a) School of Chemistry, University of Nottingham, University Park, NG7 2RD, UK.

b) Nanoscale and Microscale Research Centre, University of Nottingham, University Park, NG7 2RD, UK.

E-mail: Andrei.Khlobystov@nottingham.ac.uk

Keywords: oxidative desulphurisation, nanoreactors, nanosponges, carbon nanotubes, molybdenum dioxide

We have demonstrated the principle of a 'catalytic nanosponge' that combines the catalysis of organosulphur oxidation and sequestration of the products from reaction mixtures. Group VI metal oxide nanoparticles $\left(\mathrm{CrO}_{\mathrm{x}}, \mathrm{MoO}_{\mathrm{x}}, \mathrm{WO}_{\mathrm{x}}\right)$ are embedded within hollow graphitised carbon nanofibres (GNF) which act as nanoscale reaction vessels for oxidation reactions and permit investigation of their use in the decontamination of fuel. When immersed in a model liquid alkane fuel contaminated with organosulphur compounds (benzothiophene, dibenzothiophene, dimethyldibenzothiophene), we found that $\mathrm{MoO}_{2} @ \mathrm{GNF}$ nanoreactors comprising $30 \mathrm{~nm}$ molybdenum dioxide nanoparticles grown within the channel of GNF showed superior abilities towards oxidative desulphurisation (ODS), affording over $98 \%$ fuel desulphurisation at only $5.9 \mathrm{~mol} \%$ catalyst loading. The roles of the carbon nanoreactor in $\mathrm{MoO}_{2} @ \mathrm{GNF}$ is to enhance the activity and stability of catalytic centres over at least five cycles. Surprisingly, the nanotube cavity is able to selectively absorb and remove the ODS products (sulfoxides and sulfones) from several model fuel systems. This effect is related to the adsorptive desulphurisation (ADS) mechanism, which in combination with ODS within the same material, yields a 'catalytic nanosponge' $\mathrm{MoO}_{2} @ \mathrm{GNF}$. This innovative ODS and 


\section{WILEY-VCH}

ADS synergistic functionality negates the need for a solvent extraction step in fuel desulphurisation and produces ultra-low sulphur fuel.

\section{Introduction}

Despite the advancement of environment-friendly technologies, the transportation and energy industries still depend heavily on diesel fuel. However, recent trends of increased diesel consumption and the dwindling reserves of crude oil have triggered questions about satisfying the demand for the future. ${ }^{[1,2]}$ Moreover, the available sources of crude oil contain a high content of refractory sulphur compounds, which can have adverse industrial and environmental effects, including the formation of acid rain. ${ }^{[3,4]}$ Therefore, a key current research challenge concerns the development of an efficient and economically viable process to remove sulphur-containing contaminants from fuels in order to satisfy the ultra-low sulphur diesel (ULSD) regulations of less than $10 \mathrm{ppm}$ imposed by international policies. ${ }^{[5-7]}$

For industrial applications, the removal of sulphur compounds by hydrodesulphurisation (HDS) is currently the most widely utilised process; yet, it has several disadvantages, including harsh reaction conditions, high costs and limited applicability to the aromatic sulphur compounds. ${ }^{[8]}$ As a result, the development of other desulphurisation processes has been more recently explored (Figure 1). With biodesulphurisation currently hindered by low enzyme activity and stability, oxidative desulphurisation (ODS) and adsorptive desulphurisation (ADS) technologies offer more realistic promise. ${ }^{[9-11]}$ Specifically, the use of ODS to remove the refractory sulphur compounds from fuels exploits key changes in the polarity of the oxidised products relative to the parent organosulfur contaminant during extraction and has already been established for the production of ULSD. ${ }^{[12]}$ However, limiting the quantity of solvent needed to avoid fuel loss during extraction and the lack of 


\section{WILEY-VCH}

cheap, efficient and readily recoverable catalysts represent major stumbling blocks for this pathway. ${ }^{6}$ ADS has also shown reasonable success, utilising the physical adsorption of organosulphur compounds within the internal volumes of porous materials, such as zeolites, aluminosilicates and activated carbon. ${ }^{[13-15]}$ However, a new strategy for active materials with high and specific adsorption capacity for sulphur compounds is needed urgently. Therefore, significant further research is required to improve these individual strategies for ULSD production which could be based on more than one desulphurisation mechanism simultaneously, as we demonstrate in this study.

We selected molybdenum oxide because it has recently emerged as a promising material for the ODS of fuel, ${ }^{[16-18]}$ with the ease of formation of the electrophilic molybdenum peroxo intermediate species identified as the driving force for the effective oxidation of the sulphur contaminants (Figure 2). ${ }^{[19]}$ This intermediate is produced when an oxidant, such as hydrogen peroxide, reacts with the Lewis acidic sites of the metal oxide and leads to the formation of electrophilic species, essential to promote efficient ODS. In addition, the performance of molybdenum-based nanocatalysts can be optimised using support materials, which are known to both stabilise nanoparticles against sintering and promote further activity by facilitating charge transfer between the catalysts and the support material. $\mathrm{Al}_{2} \mathrm{O}_{3}, \mathrm{TiO}_{2}$ and $\mathrm{SiO}_{2}$ supports have recently been shown to improve the performance of ODS catalysts, therefore, selection of an appropriate support is key for refining the oxidative removal of sulphur contaminants in fuel. ${ }^{[20-23]}$ Among catalyst supports, hollow carbon nanostructures, such as carbon nanotubes, may offer several potential benefits for ODS catalysts. [24, 25] Hollow graphitised nanofibres (GNF) with an internal diameter of $60 \mathrm{~nm}-$ structural analogues to carbon nanotubes, but possessing nanoscale step-edges on inside - are particularly attractive as their corrugated interior surfaces promote the formation and enhance the stability of catalytic centres, ${ }^{[26-28]}$ while increasing the concentration of reactants around 


\section{WILEY-VCH}

the catalyst, without restricting the transport of reactants to and products from the internal cavity (the critical dimensions of most small molecules are typically at least two orders of magnitude smaller than the internal diameter of GNF). ${ }^{[29,30]}$ Furthermore, as porous activated carbons have shown promise in the desulphurisation of fuels via ADS, ${ }^{[31,32]}$ we anticipated that GNF, possessing the high internal surface area of nanotubes and maximal $\pi$ - $\pi$ stacking interactions between guest and host at the graphitic step-edges, may offer enhanced extraction of aromatic organosulphur contaminants, promoting simultaneous desulphurisation via both the ADS and ODS mechanisms. ${ }^{[33]}$

In this work, chromium, tungsten and molybdenum oxide nanoparticles were grown within GNF cavities to form carbon nanoreactors, with the latter extensively applied to the ODS of liquid fuels. The catalytic nanoreactor $\mathrm{MoO}_{2} @$ GNF demonstrated the best activity for ODS and revealed a surprising nanosponge effect by absorbing and sequestering the oxidised contaminants from liquid alkane fuel by ADS. The combined ADS and ODS activities within the same material lead to ultra-low sulphur fuels without solvent extraction, thus making a significant advancement towards the production of ULSD.

\section{Results and discussion}

\subsection{Synthesis and characterisation of molybdenum dioxide nanoparticles encapsulated within hollow graphitised carbon nanofibres}

The filling of hollow GNF can be readily achieved by exposing empty GNF to suitable precursors that contain the desired elements, sublime readily at relatively low temperatures, are stable in the gas-phase and decompose into the desired species using external stimuli. ${ }^{[34]}$ Molybdenum dioxide bisacetylacetonate $\left(\mathrm{MoO}_{2}(\mathrm{acac})_{2}\right)$ was thus identified as an ideal precursor and adopted for the gas-phase thermal deposition reaction. Sealing GNF and the 


\section{WILEY-VCH}

precursor under vacuum $\left(3 \times 10^{-5} \mathrm{mbar}\right)$ allows the sublimed guest-molecules to diffuse into the empty nanofibres (Scheme 1); once trapped within the nanofibre cavity, the precursor molecules are heated in an inert atmosphere to facilitate decomposition into molybdenum oxide nanoparticles entrapped in GNF $\left(\mathrm{MoO}_{\mathrm{x}} @ \mathrm{GNF}\right)$.

To confirm the oxidation state and crystallinity of the molybdenum oxide species within the composite material powder X-ray diffraction (PXRD) analysis was employed. Peaks at $2 \theta=$ 37.1 and $53.6^{\circ}$ can be clearly observed in the diffractogram, consistent with the crystal phase of molybdenum(IV) dioxide (Figure 3a). ${ }^{[35]}$ Thermogravimetric analysis (TGA) showed the loading (by weight) of the metal oxides in the final composite as $4.0 \%$ (Figure $3 \mathbf{b}$ ). In addition, TGA also indicates a significant reduction in the combustion temperature of the GNF by more than $150{ }^{\circ} \mathrm{C}$, indicating intimate contact between the nanoparticles and the nanofibre which are important for the catalytic performance in ODS. ${ }^{[28]}$ Energy dispersive Xray (EDX) spectroscopy reveals the elemental composition of the $\mathrm{MoO}_{2} @ \mathrm{GNF}$, with a near 2:1 atomic ratio of oxygen to molybdenum, further supporting the formation of the dioxide species (Figure 3c).

To evaluate the size, morphology and position of the molybdenum dioxide nanoparticles within GNF, transmission electron microscopy (TEM) is essential. Statistical analysis of images taken from multiple parts of the specimen grid indicates nanoparticles with an average diameter of $29 \pm 10 \mathrm{~nm}$ are found predominantly within the internal cavity of the GNF, with their distinctive contrast relative to the carbon of the GNF strongly supporting the formation of metal oxide (Figure 4b). Thus, this technique offers superior control over the size and location of metal oxide nanoparticles inside hollow carbon nanofibres relative to previously reported electrospinning approaches. ${ }^{[36]}$ The interior surfaces appear to be the favoured site for the growth of nanoparticles relative to the external walls, confirming the importance of 


\section{WILEY-VCH}

step-edges which provide anchoring points for the nucleation of the metal oxide, which are absent on the smooth graphitic layers of the exterior. High resolution TEM of the nanoparticles reveals a d-spacing of $0.37 \mathrm{~nm}$ which corresponds to the set of (110) lattice planes of $\mathrm{MoO}_{2}$ (Figure 4c). Scanning transmission electron microscopy (STEM) in combination with EDX elemental mapping additionally confirms the composition of the nanoparticles as molybdenum and oxygen (SI - Figure S1). To extract information on the 3D structure of the nanoparticles, images were captured at different extents of angular tilt (Figure 4d). As the GNF is rotated around its growth axis it can be observed that the $\mathrm{MoO}_{2}$ nanoparticles remain within the interior channel confirming their confinement within the internal volume without hindering transport resistance and exhibit faceted morphologies.

To probe the ability to control the structure and composition of the metal oxide nanoparticles by post-synthesis treatments, small quantities of the sample were heated to elevated temperatures in air (Figure 5a). The previous TGA measurements (Figure 2b) indicate that thermal treatment at $270{ }^{\circ} \mathrm{C}$ results in a transformation from $\mathrm{MoO}_{2}$ to $\mathrm{MoO}_{3}$; this transition was additionally observed in the in situ PXRD, with peaks at $2 \theta=27.4,33.9$ and $39.3^{\circ}$ observed above $250{ }^{\circ} \mathrm{C}$ consistent with the formation of $\mathrm{MoO}_{3}$. In addition, the thermal treatment resulted in an increase of the $\mathrm{MoO}_{3}$ particle size to $63 \pm 22 \mathrm{~nm}$ (Figure 5c). Therefore, this strategy offers an effective mechanism for controlling both the size and composition of the metal oxide nanoparticles. Moreover, the large number of possible group VI precursors that readily sublime at low to moderate temperatures opens the door for a broad range of different catalytic nanoreactors that can be readily afforded and manipulated using this simple versatile strategy (Figures 5d and e).

\subsection{Catalytic performance of $\mathrm{MoO}_{2} @$ GNF towards oxidative desulphurisation of fuel}




\section{WILEY-VCH}

To appraise the hybrid material for its ability to desulphurise fuel, a model system comprising 500 ppm dibenzothiophene (DBT) in $n$-hexane was identified. ${ }^{[37,38]}$ DBT was selected as it is commonly found in oil, thus presenting a real and important environmental issue in its own right, and has distinctive absorption features in the UV-Vis spectrum, ensuring facile measurement of its concentration in model fuels (SI - Figure S2). The aliphatic hydrocarbon $n$-hexane is a common constituent of fuel and represents a valuable model fuel simulant used in previous research. ${ }^{[39]}$

In a typical ODS procedure, an organic peroxide - employed to avoid potential phase transfer limitations - in a ratio of 1:20 (S:O) was added to the model fuel and catalyst and stirred at $60{ }^{\circ} \mathrm{C}$ for 120 minutes. ${ }^{[6,21,37,39]}$ Consistent with previous studies, we subsequently employed an extraction procedure in which the model fuel was vigorously stirred with acetonitrile (in a 1 to 5 ratio of extractant to fuel) for 30 minutes. ${ }^{[21,38]}$ Acetonitrile was selected as the solvent due to its known effectiveness towards the extraction of the DBT oxidation products and its reduced toxicity relative to other commonly utilised extraction solvents, such as dimethylformamide. ${ }^{[40]}$ Interestingly, it was noted that 27-30\% of DBT can be removed from the fuel simply through extraction alone, reflecting the moderate solubility of DBT in $n$ hexane. This was confirmed by treating the model fuel with the combined ODS and extraction procedure with either no catalyst or empty GNF (Table 1, entries 1-2), both of which resulted in no DBT oxidation, but yielded DBT removal of 28.8 and $28.6 \%$ from the model fuel, respectively. These control tests clearly demonstrate that neither the extraction solvent nor empty GNF are able to desulphurise model fuel to satisfactory levels.

A $5 \mathrm{mg}$ quantity of $\mathrm{MoO}_{2} @ \mathrm{GNF}$ catalyst (containing 4 wt. \% $\mathrm{MoO}_{2}$ ) was then added to the model fuel to assess its ability to remove the contaminants by ODS. Remarkably, after 120 minutes of the ODS reaction and subsequent solvent extraction $98.8 \%$ removal of the DBT 


\section{WILEY-VCH}

from the model fuel was achieved (Table 1, entry 3 and Figure 6a). Experiments conducted using shorter reaction times, but with variable quantities of catalyst, indicated that in principle even more effective sulphur removal could be realised by increasing the loading of $\mathrm{MoO}_{2} @$ GNF present in the reaction mixture (SI - Table S1). ${ }^{1} \mathrm{H}$ NMR spectroscopy and GCMS of the combined sulphur contaminants in the solvent extraction phase and the washed solid catalyst confirms the high efficiency of DBT oxidation (96.8\% conversion) leading predominantly to the doubly oxidised sulfone product (SI - Figure S3). The driving force for effective oxidation of the sulphur contaminants using our catalytic nanoreactors strongly relates to the environment at which the catalyst resides, with both modulated surface reactivity and heightened local concentrations of the contaminant at GNF step-edge where the catalyst is located, as previously demonstrated for reactions of hydrosilylation. ${ }^{[27]}$

To further explore the importance of step-edges, a sample of $\mathrm{MoO}_{2}$ on graphite was produced (SI - Figure S4). Graphite flakes provide anchoring sites for the catalyst, akin to GNF, but no confinement as inside the GNF. The results of catalyst performance showed that DBT oxidation still occurred, yet to a lesser extent than observed using $\mathrm{MoO}_{2} @ \mathrm{GNF}$, with a reduction of $27 \%$ in organosulphur removal noted (Table 1, entry 5). This supports the notion that confinement of catalysts within GNF nanoreactors is important, here affording smaller, more active, nanoparticles (SI - Figure S5) and higher local concentrations of DBT molecules at the GNF internal step-edges relative to the smoother surfaces of graphite, both of which enhance ODS activity. Moreover, TEM indicates that after the ODS reaction $\mathrm{MoO}_{2}$ nanoparticles remain practically unchanged inside GNF, thus the interior of GNF provides the ideal protective environment, inhibiting nanoparticle desorption and leaching, ensuring the reuse of the catalyst in subsequent ODS reactions (SI - Figure S6). 


\section{WILEY-VCH}

Interestingly, initial attempts to reuse the $\mathrm{MoO}_{2} @ \mathrm{GNF}$ catalyst were only moderately successful, with an approximately $40 \%$ drop in sulphur removal capacity noted after the first cycle (red bars, Figure 6b). Analysis of $\mathrm{MoO}_{2} @$ GNF after the first ODS reaction by PXRD (Figure 6c) revealed the presence of a mixture of organic molecules held within GNF, comprising predominantly $\mathrm{DBTO}_{2}$, a small amount of DBTO, but importantly no DBT. Complementary TGA (Figure 6d) of the used $\mathrm{MoO}_{2} @$ GNF catalyst confirmed the presence of $\mathrm{DBTO}_{2}$ inside GNF, with a significant mass loss at $242{ }^{\circ} \mathrm{C}$ consistent with the boiling point of the sulfone product (SI - Figure S7) noted. Moreover, ${ }^{1} \mathrm{H}$ NMR spectroscopy analysis of the organic material removed from the internal channel of GNF by subsequent washing of the solid catalyst (SI - Figure S8) confirmed that only DBTO and $\mathrm{DBTO}_{2}$ become adsorbed and trapped within the GNF in significant quantities. Whilst our adsorption experiments (SI Table S2) indicate that $\mathrm{MoO}_{2} @$ GNF only uptakes negligible quantities of DBT from solution by ADS, analysis of the catalyst after its first use provides compelling evidence that enhanced removal of sulphur contaminants can be achieved here by selective adsorption and retention of the products of ODS reaction, i.e. adsorptive desulphurisation by sequestration of DBTO sulfoxide and $\mathrm{DBTO}_{2}$ sulfone. This is consistent with a previous study which indicated that the adsorption affinity of porous carbons was significantly greater for $\mathrm{DBTO}_{2}$ than DBT. ${ }^{[41]}$ From a practical point of view, accumulation of the ODS products necessitates an additional thermal or solvent treatment between uses of catalytic nanoreactors $\mathrm{MoO}_{2} @ \mathrm{GNF}$ in order to maintain the high sulphur removal capacity use-to-use (green bars, Figure 6b). However, this nanosponge effect ensures efficient removal of the sulphur contaminants through a combination of ODS and ADS, thus potentially negating the requirement for a separate and costly additional extraction step (Figure 7a).

In light of this, we next considered the efficiency of sulphur contaminant removal in the absence of solvent extraction step, with over $90 \%$ removal of the DBT observed (Table 1, 


\section{WILEY-VCH}

entry 3). Kinetic analysis indicates a pseudo-linear removal of DBT up to 60 minutes, yielding $78 \%$ total sulphur removal; after this, the rate of removal decreases from a combination of the expected decrease in DBT concentration as the reaction proceeds and slower diffusion inside the GNF internal channel due to accumulation of the products of DBT oxidation inside nanoreactors (Figure 7b). However, after 60 minutes the level of sulphur contaminants within the fuel approaches that which is required to meet current ULSD regulations. Similarly, the decrease in activity of $\mathrm{MoO}_{3} @ \mathrm{GNF}$ (Table 1, entry 4) is a consequence of the confined catalysts growing to the diameter of the nanofibre resulting in blocking of the internal cavity and subsequently restricting access of reactants to the confined catalyst. Given the low catalyst loading in our experiments, our catalytic nanoreactors $\mathrm{MoO}_{2} @ \mathrm{GNF}$ significantly outperform other catalysts in their ability to desulphurise fuel by more than an order of magnitude (SI - Table S3). ${ }^{[21,39,42,43]}$

To assess the effectiveness of the $\mathrm{MoO}_{2} @$ GNF catalysts towards real fuel systems a more sterically demanding contaminant (dimethyl dibenzothiophene - DMDBT) and an electronpoor contaminant (benzothiophene - BT) were investigated alongside DBT in $n$-octane as a more representative fuel. No effect of solvent, i.e. $n$-hexane $v s . n$-octane, was noted in the sole oxidation of DBT (SI - Table S4). From a comparison of the sulphur removal efficiency of GNF and $\mathrm{MoO}_{2} @$ GNF (including and without the solvent extraction) after 18 hours, it is clear that $\mathrm{MoO}_{2} @ \mathrm{GNF}$ is effective towards oxidation of organosulphur species, with the nanosponge able to remove the oxidised contaminants from the mixed fuel system (Table 2), with the order of reactivity of these contaminants shown to be DMDBT $>$ DBT $>$ BT. After 2 hours, it was found that there was almost $100 \%$ removal of DMDBT. The reason for this is thought to be related to the higher affinity of DMDBT for GNF which encourages absorption into the internal channel of the nanoreactors and leads to a high concentration of DMDBT at the location of the catalyst. This is supported by the observation of a small decrease in the 


\section{WILEY-VCH}

removal of DBT in the mixed system from what would be expected after 2 hours in isolation, indicative of competition within the nanoreactor of DMDBT and DBT for access to the catalyst (Table 2 - values in parentheses). After an 18 hour ODS procedure, all of the DMDBT and DBT can be effectively oxidised and removed by the solid nanosponge extraction process (SI - Table S5). Although BT can be oxidised by the catalyst, the rate of oxidation is lower than the other contaminants, requiring 18 hours for the near total $(95 \%)$ removal. In all these reactions $\mathrm{MoO}_{2} @ \mathrm{GNF}$ not only promotes the ODS reactions but also absorbs the products of oxidation via the ADS mechanism leading to desulphurisation at ULSD regulations.

\section{Conclusion}

In this study, we demonstrate that catalytic nanoreactors employed in the desulphurisation of liquid fuels play a dual role of catalyst and nanosponge - simultaneously promoting the reactions of oxidation of organosulphur species and absorbing their products from a model fuel. Several group VI metal oxide nanoparticles were grown inside GNF hollow carbon nanofibres were found to form stable materials with well-defined and controlled structure and composition. Molybdenum (IV) oxide nanoparticles within GNF $\left(\mathrm{MoO}_{2} @ \mathrm{GNF}\right)$ showed the best catalytic activity resulting in over $95 \%$ desulphurisation by utilising the nanosponge's abilities to selectively absorb the oxidised products. ULSD levels of mixed and individual organosulphur contaminated model fuels can be achieved by applying the nanosponge or combined solvent extraction procedure. Confinement of catalytic centres in GNF allows effective reuse of the nanoreactors for at least five cycles with no significant loss of activity. Importantly, the dual ODS and ADS functionality of $\mathrm{MoO}_{2} @$ GNF material negates the need for need for the extraction stage, leading directly to the removal of over $95 \%$ of organosulphur contaminants from the liquid alkane fuels. 


\section{WILEY-VCH}

\section{Experimental Section}

\subsection{General}

Standard reagents, including 4,6-dimethyldibenzothiophene (97\%), benzothiophene (98\%) and thiophene (>99\%), and solvents were purchased from Sigma-Aldrich Chemicals and were used as purchased. Additional reagents were obtained from the following sources: dibenzothiophene (98\%, Acros Chemicals), $n$-octane (95\%, VWR Chemicals), $n$-hexane (98.5\%, Fischer Scientific), tert-butyl hydroperoxide (70\% aqueous solution, Alfa Aesar) and bis(acetylacetonato)dioxymolybdenum(VI) $\left(\mathrm{MoO}_{2}\left(\mathrm{CH}_{3} \mathrm{COCHCOCH}_{3}\right)_{2} \quad(99 \%\right.$, Alfa Aesar). Graphitised nanofibres (PR19-XT-HHT carbon nanofibres, iron content <100ppm) were purchased from Pyrograf Products Inc.

Transmission electron microscopy and dark field scanning transmission electron microscopy were performed using a JOEL JEM-2100Plus microscope operated at 200KeV. TEM samples were prepared via a drop casting technique, where samples were first dispersed in methanol and deposited on a copper grid mounted "lacey" carbon films. All images were processed using Gatan Digital Micrograph. Energy dispersive X-ray spectroscopy and mapping were acquired for samples mounted on the TEM grid using an Oxford Instruments INCA X-ray microanalysis system. The beam was condensed on to areas suspended over holes of the amorphous carbon film to eliminate contributions from the support film itself. The copper and silicon peak signals, associated with the grid mesh and an artefact of grid fabricated, were removed.

Thermogravimetric analysis was performed using a TA Q500 Thermogravimetric Analyser. All samples were analysed using a platinum pan and in the presence of air. The parameters for 


\section{WILEY-VCH}

all experiments were: Ramp $5{ }^{\circ} \mathrm{C} /$ minute from $20-1000{ }^{\circ} \mathrm{C}$ with an isotherm for 10 minutes at $1000{ }^{\circ} \mathrm{C}$, air flow: $60 \mathrm{~mL} / \mathrm{minute}$.

The powder X-ray measurements were performed using a PANalytical X'Pert Pro diffractometer equipped with a $\mathrm{Cu} \mathrm{K}(\alpha)$ radiation Source $(\lambda=1.5432,40 \mathrm{kV} 40 \mathrm{~mA})$ in BraggBrentano geometry using a Si zero background holder. All samples were wetted with isopropyl alcohol to aid GNF adhesion. The parameters for a typical experiment were: Start angle: $5^{\circ}$, Stop angle: $80^{\circ}$, Step size: $0.0525^{\circ}$, Time/step: 6080 s, Scan speed: $0.00220^{\circ}$ s. High temperature PXRD measurements were performed using an Anton Parr (HTK 1200N) high temperature oven chamber in air up to $450{ }^{\circ} \mathrm{C}$.

UV/Vis absorption spectra were recorded at room temperature using $1 \mathrm{~cm}$ quartz cuvettes. The samples were run using a Perkin-Elmer Lambda 25 UV/Vis spectrometer at a scan rate of $240 \mathrm{~nm} / \mathrm{min}$ over a wavelength range of $200-500 \mathrm{~nm}$. Spectra were analysed using UV WinLab ES software. For all analysis, $30 \mu \mathrm{L}$ of the treated model fuel was diluted using 2.5 $\mathrm{ml}$ of the same solvent.

${ }^{1} \mathrm{H}$ NMR spectroscopy spectra were recorded in $\mathrm{CD}_{3} \mathrm{CN}$ at room temperature using a Bruker AVANCE DPX-300 spectrometer (TopSpin 1.3 PL4) in Wilmad NMR tubes (5mm diameter). Spectra were analysed using MestReNova software.

Samples were analysed by GC-MS using a Thermo Scientific ISQ-LT single quadrupole mass spectrometer, attached to a Thermo Scientific Trace 1300 GC. Samples were injected through a Thermo Scientific TriPlusRSH liquid autosampler onto a Thermo Scientific TG5MS GC column (15 m x $0.25 \mathrm{~mm} \times 0.25 \mathrm{um})$. Instrument conditions were as follows: GC injector temperature $200{ }^{\circ} \mathrm{C}$; injections were performed in split mode, employing a 50:1 split ratio. 


\section{WILEY-VCH}

The $\mathrm{GC}$ oven temperature programme was $40{ }^{\circ} \mathrm{C}(3 \mathrm{~min})$ to $320^{\circ} \mathrm{C}(10 \mathrm{~min})$ at $5{ }^{\circ} \mathrm{C} \mathrm{min}^{-1}$. The GC carrier gas was helium, with a column flow of $1 \mathrm{~mL} \mathrm{~min}{ }^{-1}$. The mass spectrometer was programmed to acquire data after a 3 minute delay, over the mass range 50-600 Da, with a $0.2 \mathrm{~s}$ scan time. Mass spectra were acquired in EI mode ( $70 \mathrm{eV}$ ionisation energy). The ion source temperature was $200{ }^{\circ} \mathrm{C}$ and the MS transfer line was maintained at $250{ }^{\circ} \mathrm{C}$. Total Ion Current chromatograms and associated mass spectra were processed with Chromeleon software (Version 7.2; Thermo Fisher Scientific Inc., Massachusetts, USA).

\subsection{Preparation of $\mathrm{MO}_{\mathrm{x}} @ \mathrm{GNF}$}

The molybdenum dioxide catalyst was synthesised by first pre-treating PR19 graphitised nanofibres, to remove any moisture, by heating below their oxidation temperature $\left(500{ }^{\circ} \mathrm{C}\right)$ in air for 1 hour. The pre-treated graphitised nanofibres $(60 \mathrm{mg})$ were then loaded into a Pyrex glass tube $(\mathrm{d} 10 \mathrm{~mm}, \mathrm{~L} 6 \mathrm{~cm})$ with molybdenum dioxide bisacetylacetonate $(11.1 \mathrm{mg})$ and sealed under vacuum $\left(\sim 5 \times 10^{-5}\right.$ mbar $)$. The sealed vessel was then heated to $160{ }^{\circ} \mathrm{C}$ for 2 days. Following sublimation and prior to opening, the Pyrex glass tube was immediately cooled for 5 minutes. $\mathrm{MoO}_{2}(\mathrm{acac})_{2} @ \mathrm{GNF}$ were placed into a new Pyrex glass tube $(\mathrm{d} 10 \mathrm{~mm}, \mathrm{~L} 6 \mathrm{~cm})$ and evacuated and backfilled with argon (repeated 3 times) to remove any oxygen or moisture present. Before sealing, the Pyrex glass tube was filled with argon gas ( 0.5 bar). For the decomposition step, the sealed vessels were heated at $500{ }^{\circ} \mathrm{C}$ for 1 hour in a pre-heated furnace to obtain the $\mathrm{MoO}_{2} @$ GNF composite material which was then cooled down slowly for 9 hours. $\mathrm{MoO}_{2} @$ graphite composite was synthesised using the same method with a graphite flakes powder to $\mathrm{MoO}_{2}(\mathrm{acac})_{2}$ ratio of $5.6 \mathrm{mg}: 30 \mathrm{mg}$. For the tungsten/chromium oxide encapsulated species the same procedure was followed with a tungsten hexacarbonyl precursor $\left(6.8 \mathrm{mg}\right.$, sublimation temperature; $\left.120{ }^{\circ} \mathrm{C}\right)$ or chromium acetylacetonate precursor (25.0 mg, sublimation temperature; $160{ }^{\circ} \mathrm{C}$ ). Post synthesis thermal manipulation of the 


\section{WILEY-VCH}

$\mathrm{MoO}_{2} @ \mathrm{GNF}$ composite required heating at $350{ }^{\circ} \mathrm{C}$ in air for $30 \mathrm{mins}$ and cooled slowly over 2 hours to form $\mathrm{MoO}_{3} @ \mathrm{GNF}$.

\subsection{Oxidative desulphurisation procedure}

The first model fuel (500 mg/L of sulphur) was prepared by dissolving DBT $(0.870 \mathrm{~g}, 4.72$ mmol) in $300 \mathrm{ml} n$-hexane. The second mixed component model fuel contains benzothiophene (125 ppm), dibenzothiophene (125 ppm) and dimethyl dibenzothiophene (125 ppm) in $n$-octane. The desulphurisation experiments were conducted at $60{ }^{\circ} \mathrm{C}$. In general, 5 $\mathrm{mg}$ of catalyst was added to $5 \mathrm{~mL}$ of the model fuel and sonicated for 2 minutes. $0.14 \mathrm{ml}$ of 70 wt. \% TBHP aqueous solution was added and the solution was refluxed for 120 minutes unless otherwise stated and stirred at $500 \mathrm{rpm}$. Once complete, the solid was removed and the reaction products extracted using $1 \mathrm{~mL} \mathrm{CH}_{3} \mathrm{CN}$. The extraction process was vigorously stirred at a constant speed $(1000 \mathrm{rpm})$ for 30 minutes at ambient temperature. The removed catalyst was washed with deuterated solvent and the washings were combined with the extraction layer. For the recycling experiments where no catalyst washing was performed between subsequent uses (red bars, Figure 6b) the solid catalyst was separated from the reaction mixture by filtration, without an extraction into acetonitrile, and dispersed directly as a solid in the model fuel of successive reactions. The extraction phase and organic fuel layer were separated and separately analysed: the $n$-hexane layer by GC-MS, UV-Vis and ${ }^{1} \mathrm{H}$ NMR spectroscopies; the extraction layer using GC-MS and ${ }^{1} \mathrm{H}$ NMR spectroscopy. The oxidation of DBT was monitored by the disappearance of the characteristic chemical shifts between 8.28-8.21 ppm (m, 2H). Confirmation of the sulfoxide and sulfone products was afforded by monitoring by the integrals between 7.71-7.64 $(\mathrm{t}, 2 \mathrm{H})$ and 7.86-7.81 $(\mathrm{d}, 2 \mathrm{H})$, respectively. The treated diesel was stored in a sealed vial and kept refrigerated at $2{ }^{\circ} \mathrm{C}$. GC-MS retention times for organosulphur compounds were: $\mathrm{DBT}=25.27, \quad \mathrm{DBTO}=32.23, \quad \mathrm{DBTO}_{2}=32.51$; 


\section{WILEY-VCH}

$\mathrm{DMDBT}=29.27, \mathrm{DMDBTO}=34.67, \mathrm{DMDBTO}_{2}=34.48 ; \mathrm{BT}=11.94, \mathrm{BTO}=21.54, \mathrm{BTO}_{2}=22.18$

mins.

The desulphurisation experiments without the solvent extraction were conducted as previously mentioned at $60{ }^{\circ} \mathrm{C}$. In general, $5 \mathrm{mg}$ of catalyst was added to $5 \mathrm{~mL}$ of the model fuel and sonicated for 2 minutes. $0.14 \mathrm{ml}$ of $70 \mathrm{wt}$. \% TBHP aqueous solution was added and the solution was refluxed for 120 minutes unless otherwise stated and stirred at $500 \mathrm{rpm}$. Once complete, the solid was removed, with resultant organic phase and washed solid catalyst analysed using the techniques stated above.

\section{Supporting Information}

Supporting Information is available from the Wiley Online Library or from the author.

\section{Acknowledgements}

The authors would like to thank the Centre for Sustainable Chemistry (CSC), University of Nottingham, and the Engineering and Physical Science Research Council (EPSRC) for supporting this research, and the Nanoscale and Microscale Research Centre (nmRC) for access to the electron microscopy facilities.

Received: ((will be filled in by the editorial staff))

Revised: ((will be filled in by the editorial staff)) Published online: ((will be filled in by the editorial staff))

\section{References}

[1] S. Mohankumar, P. Senthilkumar, Renew. Sust. Energ. Rev., 2017, 80, 1227-1238.

[2] A. K. Agarwal, Prog. Energy Combust. Sci., 2007, 33, 233-271.

[3] G. Mohebali, A. S. Ball, Int. Biodeterior. Biodegrad., 2016, 110, 163-180.

[4] V. C. Srivastava, RSC Adv., 2012, 2, 759-783. 


\section{WILEY-VCH}

[5] H. A. El Sayed, A. M. A. El Naggar, B. H. Heakal, N. E. Ahmed, S. Said, A. A. H. Abdel-Rahman, Fuel, 2017, 209, 127-131.

[6] E. Ito, J. A. R. van Veen, Catal. Today, 2006, 116, 446-460.

[7] P. S. Kulkarni, C. A. M. Afonso, Green Chem., 2010, 12, 1139-1149.

[8] J. Bu, G. Loh, C. G. Gwie, S. Dewiyanti, M. Tasrif, A. Borgna, Chem. Eng. J., 2011, $166,207-217$.

[9] M. Armaghan, M. M. Amini, H. R. Khavasi, W. H. Zhang, S. W. Ng, RSC Adv., 2016, $6,85381-85389$.

[10] L. H. Zhang, J. Y. Wang, Y. L. Sun, B. Jiang, H. W. Yang, Chem. Eng. J., 2017, 328, 445-453.

[11] J. Wang, R. R. Butler, F. Wu, J. F. Pombert, J. J. Kilbane, B. C. Stark, PLoS One, 2017, 12, 20.

[12] M. F. Ali, A. Al-Malki, B. El-Ali, G. Martinie, M. N. Siddiqui, Fuel, 2006, 85, 13541363.

[13] R. T. Yang, A. J. Hernandez-Maldonado, F. H. Yang, Science, 2003, 301, 79-81.

[14] A. R. Lopes, A. D. Scheer, G. V. Silva, C. I. Yamamoto, Materia, 2016, 21, 407-415.

[15] E. Deliyanni, M. Seredych, T. J. Bandosz, Langmuir, 2009, 25, 9302-9312.

[16] D. H. Wang, E. W. H. Qian, H. Amano, K. Okata, A. Ishihara, T. Kabe, Appl. Catal., $A, \mathbf{2 0 0 3}, 253,91-99$.

[17] M. A. Safa, X. L. Ma, Fuel, 2016, 171, 238-246.

[18] L. Qiu, Y. Cheng, C. P. Yang, G. M. Zeng, Z. Y. Long, S. N. Wei, K. Zhao, L. Luo, RSC Adv., 2016, 6, 17036-17045.

[19] J. L. Garcia-Gutierrez, G. A. Fuentes, M. E. Hernandez-Teran, P. Garcia, F. MurrietaGuevara, F. Jimenez-Cruz, Appl. Catal., A, 2008, 334, 366-373.

[20] A. Bazyari, A. A. Khodadadi, A. H. Mamaghani, J. Beheshtian, L. T. Thompson, Y. Mortazavi, Appl. Catal. B-Environ., 2016, 180, 65-77. 


\section{WILEY-VCH}

[21] W. A. W. Abu Bakar, R. Ali, A. A. A. Kadir, W. Mokhtar, Fuel Process. Technol., 2012, 101, 78-84.

[22] M. Zhang, W. S. Zhu, S. H. Xun, J. Xiong, W. J. Ding, M. Li, Q. Wang, H. M. Li, Chem. Eng. Technol., 2015, 38, 117-124.

[23] Y. Q. Xu, W. M. Xuan, M. M. Zhang, H. N. Miras, Y. F. Song, Dalton Trans., 2016, 45, 19511-19518.

[24] A. La Torre, M. W. Fay, G. A. Rance, M. Del Carmen Gimenez-Lopez, W. A. Solomonsz, P. D. Brown, A. N. Khlobystov, Small, 2012, 8, 1222-1228.

[25] X. L. Pan, X. H. Bao, Acc. Chem. Res., 2011, 44, 553-562.

[26] T. H. Noh, O. S. Jung, Acc. Chem. Res., 2016, 49, 1835-1843.

[27] W. A. Solomonsz, G. A. Rance, B. J. Harris, A. N. Khlobystov, Nanoscale, 2013, 5, 12200-12205.

[28] A. La Torre, M. D. Gimenez-Lopez, M. W. Fay, G. A. Rance, W. A. Solomonsz, T. W. Chamberlain, P. D. Brown, A. N. Khlobystov, ACS nano, 2012, 6, 2000-2007.

[29] A. N. Khlobystov, ACS nano, 2011, 5, 9306-9312.

[30] S. Gupta, N. H. Tai, J. Mater. Chem. A, 2016, 4, 1550-1565.

[31] T. A. Saleh, S. A. Al-Hammadi, A. Tanimu, K. Alhooshani, J. Colloid Interface Sci., 2018, 513, 779-787.

[32] T. A. Saleh, J. Clean Prod., 2018, 172, 2123-2132.

[33] J. A. Arcibar-Orozco, J. R. Range-Mendez, T. J. Bandosz, Energy Fuels, 2013, 27, $5380-5387$.

[34] M. A. Astle, G. A. Rance, M. W. Fay, S. Notman, M. R. Sambrook, A. N. Khlobystov, J. Mater. Chem. A, 2018, 6, 20444-20453.

[35] P. X. Han, W. Ma, S. P. Pang, Q. S. Kong, J. H. Yao, C. F. Bi, G. L. Cui, J. Mater. Chem. A, 2013, 1, 5949-5954. 


\section{WILEY-VCH}

[36] R. Y. Zhuang, S. S. Yao, M. X. Jing, X. Q. Shen, J. Xiang, T. B. Li, K. S. Xiao, S. B. Qin, Beilstein J. Nanotechnol., 2018, 9, 262-270.

[37] L. P. Hou, R. X. Zhao, X. P. Li, X. H. Gao, Appl. Surf. Sci., 2018, 434, 1200-1209.

[38] A. Alizadeh, M. Fakhari, M. M. Khodeai, G. Abdi, J. Amirian, RSC Adv., 2017, 7, $34972-34983$.

[39] M. Chamack, A. R. Mahjoub, H. Aghayan, Chem. Eng. J., 2014, 255, 686-694.

[40] I. Martinez, M. E. S. Mohamed, D. Rozas, J. L. Garcia, E. Diaz, Metab. Eng., 2016, 35, 46-54.

[41] Y. W. Shi, G. Z. Liu, X. W. Zhang, Ind. Eng. Chem. Res., 2017, 56, 2557-2564.

[42] H. Y. Ji, H. T. Ju, R. Lan, P. W. Wu, J. Sun, Y. H. Chao, S. H. Xun, W. S. Zhu, H. M. Li, $R S C A d v ., 2017,7,54266-54276$.

[43] M. Chamack, A. R. Mahjoub, Catal. Lett., 2016, 146, 1050-1058.

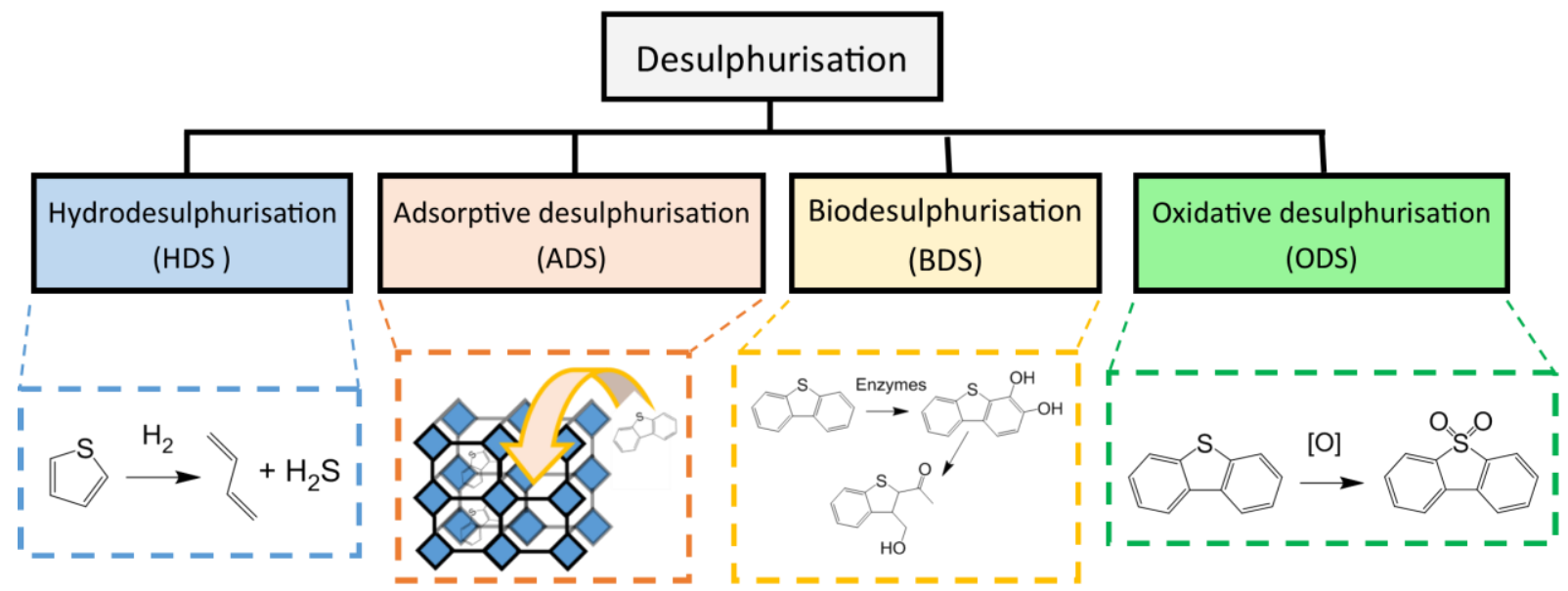

Figure 1. Current strategies for the desulphurisation of fuel. The application of hydrodesulphurisation (HDS) for aromatic sulphur compounds, such as thiophene uses hydrogen and produces $\mathrm{H}_{2} \mathrm{~S}$. Adsorptive desulphurisation (ADS) using porous media and biodesulphurisation (BDS) via the Kodama pathway in the presence of enzymes have both shown promise for the selective removal of dibenzothiophene (DBT). Oxidative 


\section{WILEY-VCH}

desulphurisation (ODS) has the greatest potential for oxidation of DBT, yielding ultra-low sulphur fuels.

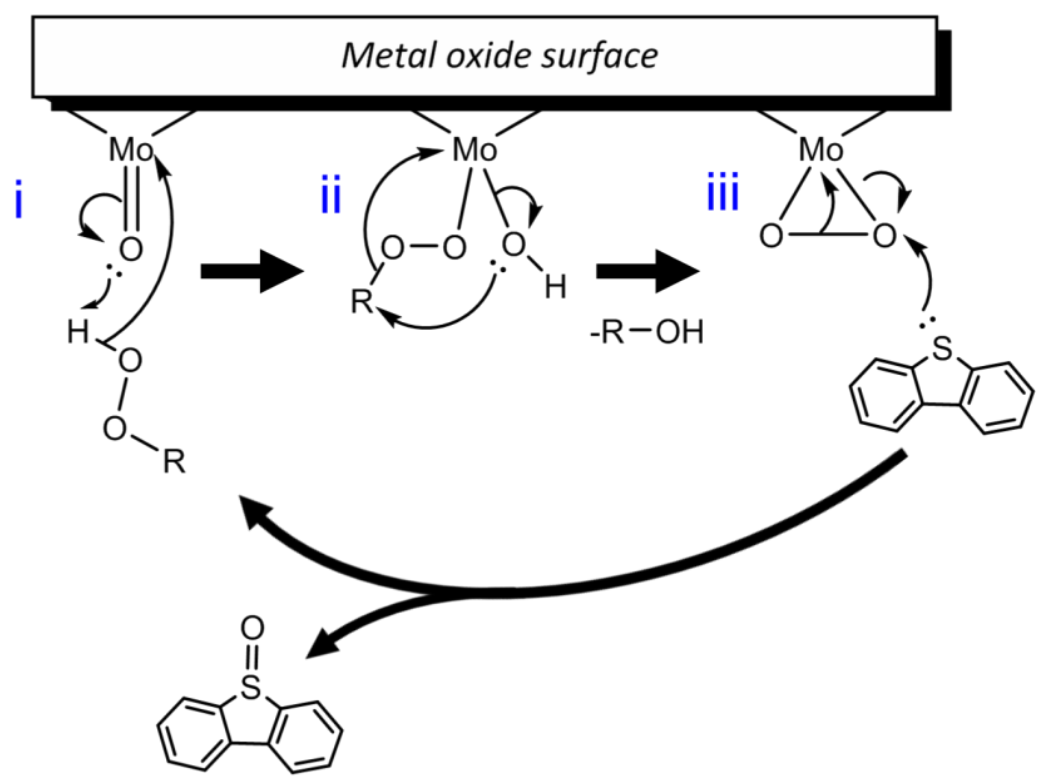

Figure 2. Mechanism for the oxidation of sulphur contaminants using molybdenum oxide catalysts with peroxide species. i) Nucleophilic attack of the peroxide forms the hydroperoxymolybdate species. ii) Reversible loss of alcohol to produce the monoperoxo species. iii) Peroxo group is activated electrophilically via coordination to the molybdenum atoms and results in a nucleophilic attack from the sulphur atom in the organosulphur species and loss of the oxidised product.



Scheme 1. Schematic diagram for the gas-phase encapsulation of $\mathrm{MoO}_{2}(\mathrm{acac})_{2}$ thermal growth of molybdenum oxide nanoparticles encapsulated within the hollow graphitised carbon nanofibres. 


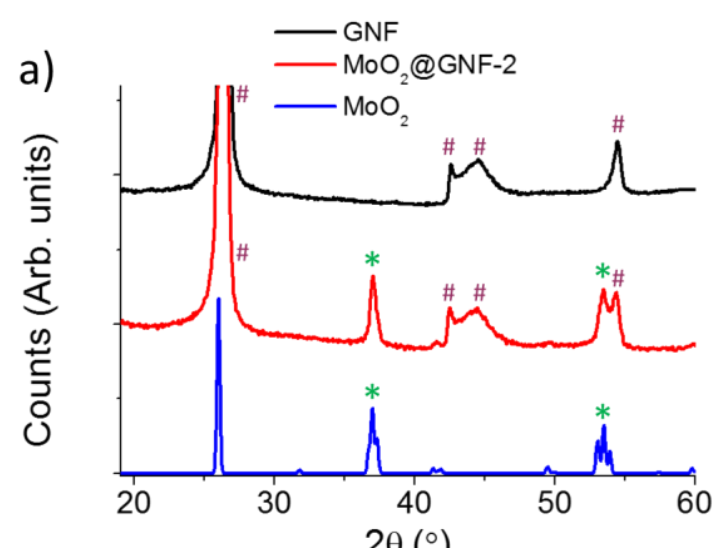

b)
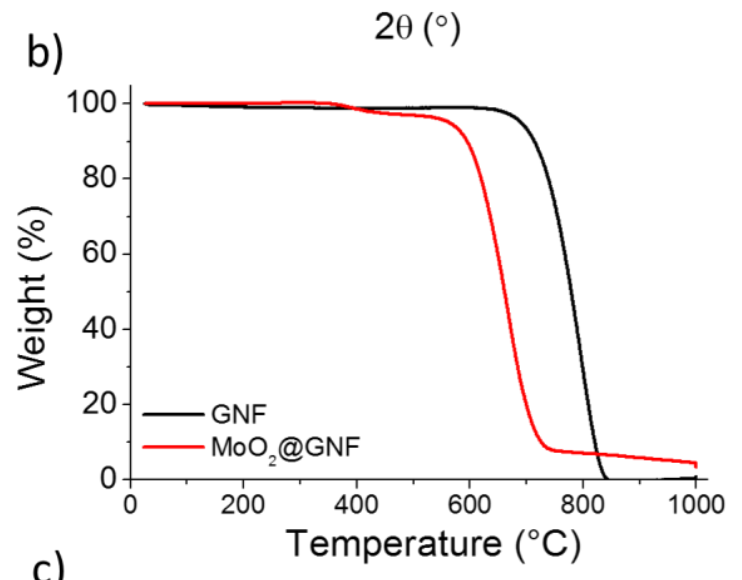

c)

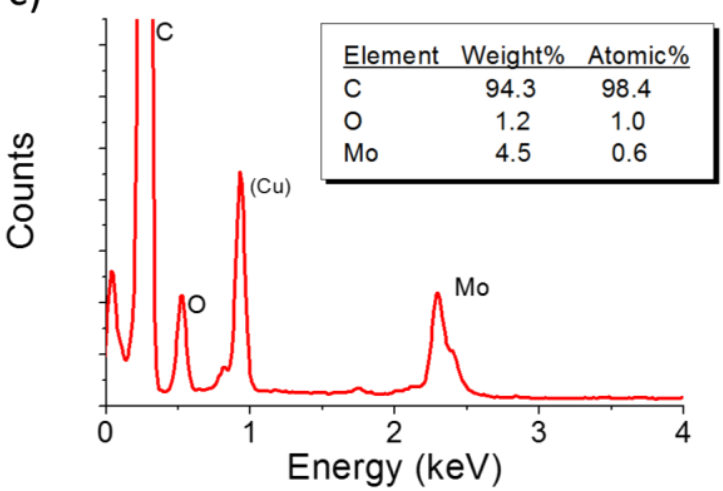

Figure 3. (a) PXRD patterns of $\mathrm{MoO}_{2} @ \mathrm{GNF}$ (red), empty GNF (black) and bulk $\mathrm{MoO}_{2}$ (blue) show the hybrid material is the combination of the two components. Grain size was estimated to be $20 \mathrm{~nm}$ based on analysis of the peak at $2 \theta=37.1^{\circ}\left(\mathrm{FWHM}=0.51^{\circ}\right)$ and application of the Scherrer equation. (b) Representative TGA of $\mathrm{MoO}_{2} @ \mathrm{GNF}$ (red) vs. GNF (black), providing a measure of the metal oxide loading. (c) EDX spectroscopy of $\mathrm{MoO}_{2} @ \mathrm{GNF}$ confirms the presence of Mo and $\mathrm{O}$ inside GNF in a ratio close to the stoichiometric in $\mathrm{MoO}_{2}$. 


\section{WILEY-VCH}
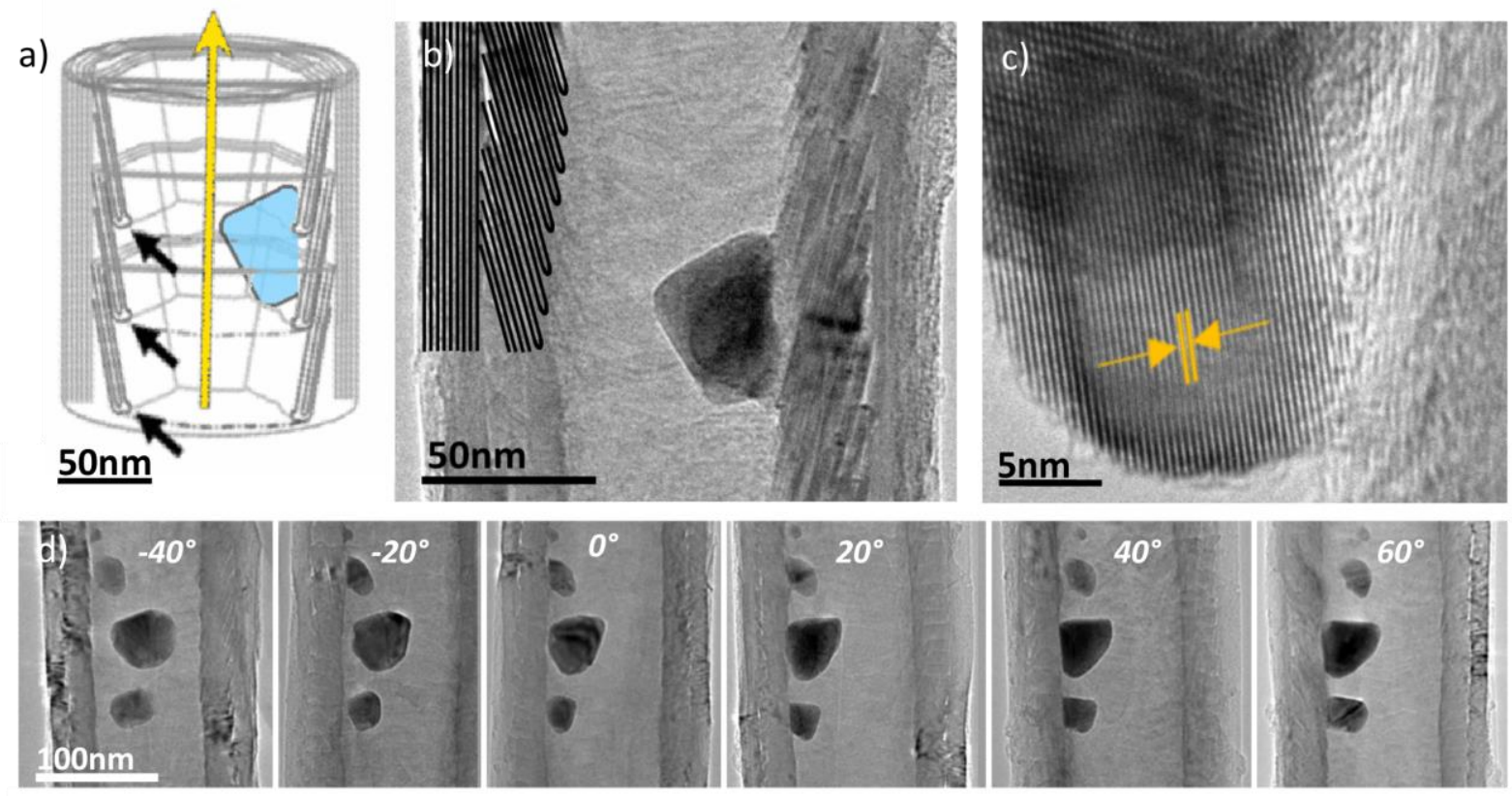

Figure 4. (a) Schematic representation of the structure of GNF (interior step-edges are denoted by black arrows; the yellow arrow signifies the direction of the nanofibre growth axis; the blue shape represents a $\mathrm{MoO}_{2}$ nanoparticle). (b) Bright field transmission electron microscopy image $\mathrm{MoO}_{2} @$ GNF. The internal step edges have been highlighted for clarity, with the $\mathrm{MoO}_{2}$ nanoparticle clearly shown residing at the interior step-edges. (c) High resolution TEM of the $\mathrm{MoO}_{2}$ nanoparticle providing a lattice spacing of $0.37 \mathrm{~nm}$, consistent with the (100) plane in $\mathrm{MoO}_{2}$. (d) TEM tilt series of $\mathrm{MoO}_{2} @ \mathrm{GNF}$, rotating around the GNF growth axis, which allows for a better understanding of the morphology of the nanoparticles and confirms their encapsulation within the internal cavity of the GNF. 


\section{WILEY-VCH}
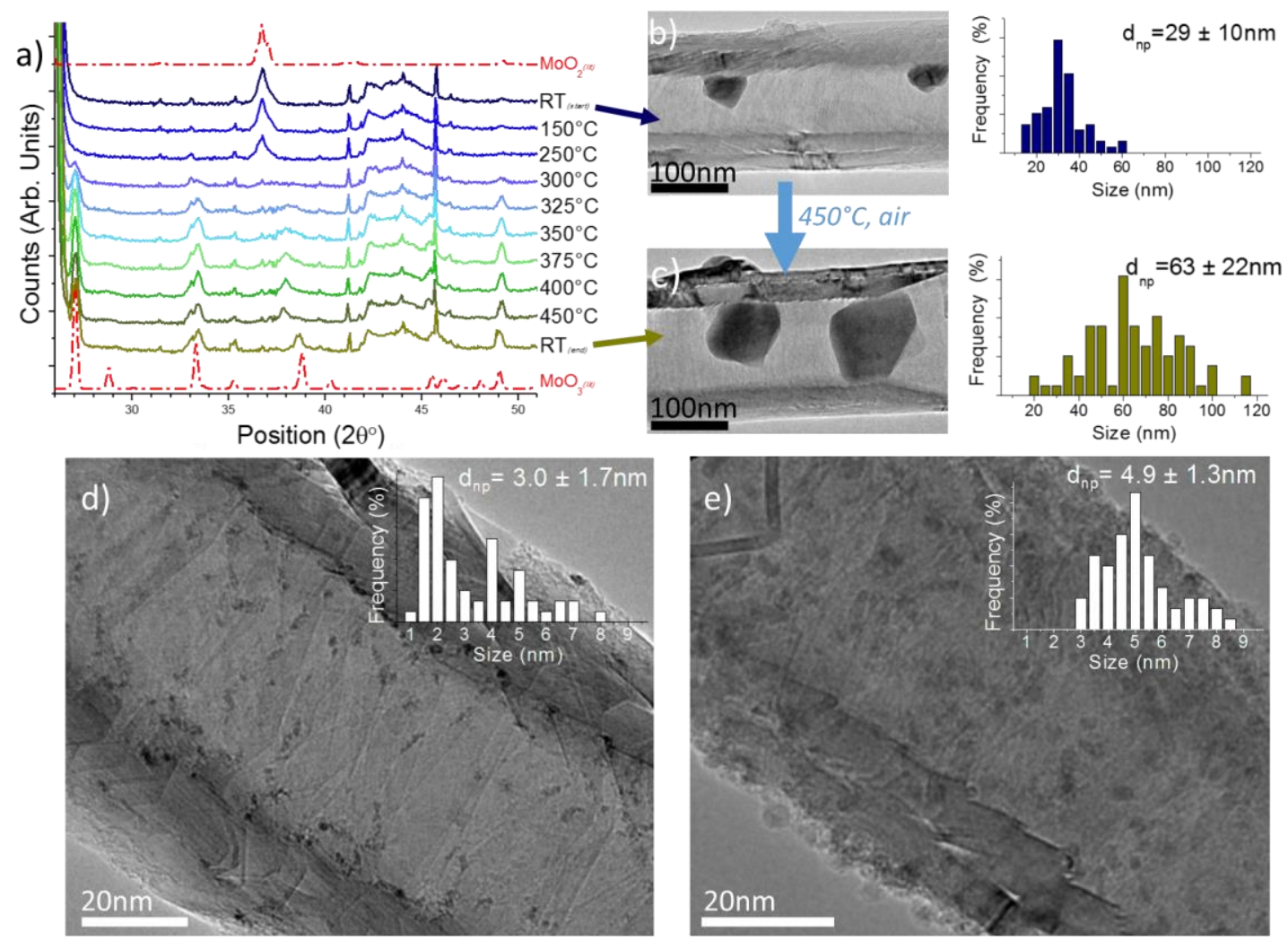

Figure 5. (a) PXRD analysis of thermal annealing $\mathrm{MoO}_{2} @ \mathrm{GNF}$ in air clearly shows the change from $\mathrm{MoO}_{2}$ to $\mathrm{MoO}_{3}$ between 250 and $300{ }^{\circ} \mathrm{C}$. (b) and (c) TEM images and corresponding nanoparticle size distributions before and after post-synthesis thermal treatment at $450{ }^{\circ} \mathrm{C}$, respectively, highlighting the increase in nanoparticle size and blocking of the GNF interior channel for materials treated at elevated temperatures. (d) and (e) TEM images of $\mathrm{WO}_{\mathrm{x}} @ \mathrm{GNF}$ (from $\mathrm{W}(\mathrm{CO})_{6}$ ) and $\mathrm{CrO}_{\mathrm{x}} @ \mathrm{GNF}$ (from $\mathrm{Cr}(\mathrm{acac})_{3}$ ) with their particle size distribution profiles, respectively. These show the potential of the gas-phase deposition technique using different precursors to produce a plethora of unique nanomaterials. 


\section{WILEY-VCH}

a)



c)

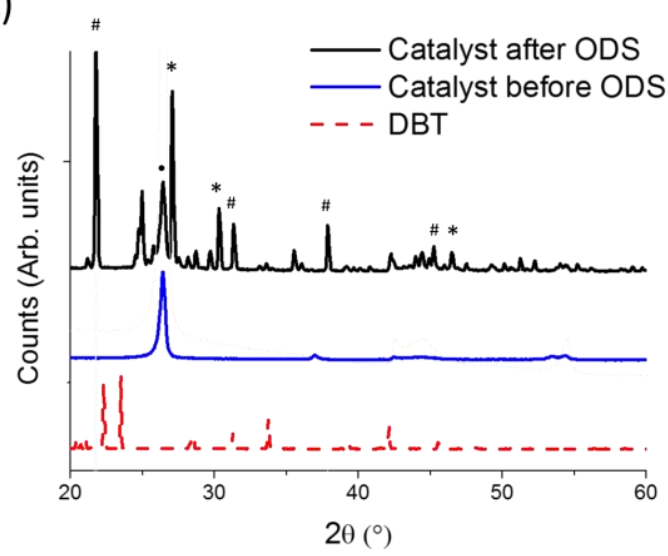

b)

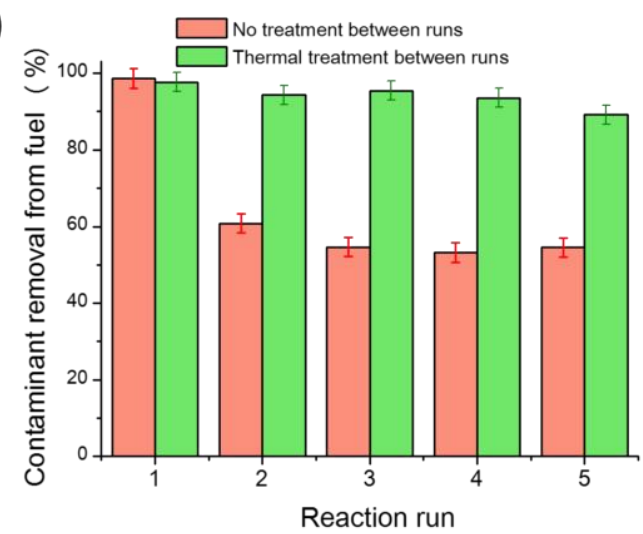

d)

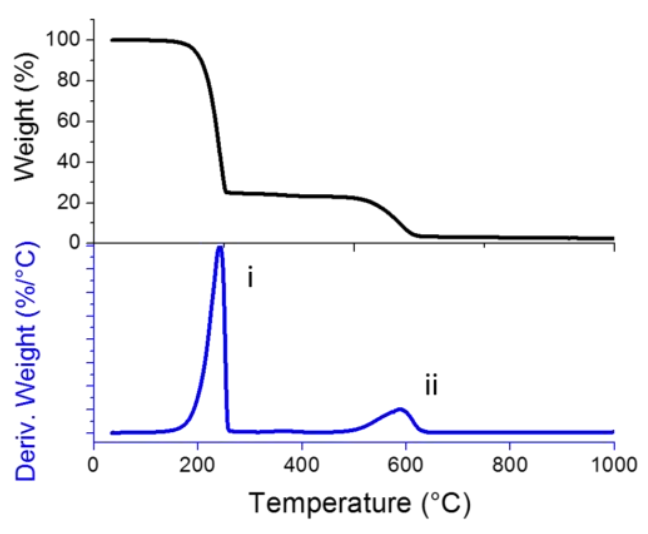

Figure 6. (a) Kinetic profile for the removal of DBT from $n$-hexane using the ODS (5 mg $\mathrm{MoO}_{2} @ \mathrm{GNF}, 5 \mathrm{ml}$ fuel, 1:20 S:O ratio, $\left.60{ }^{\circ} \mathrm{C}, 120 \mathrm{mins}\right)$ and solvent extraction $(5: 1$ hexane: acetonitrile, 30 mins) procedures. These results show that there is moderate sulphur removal from the model fuel using solvent extraction alone; however, when combined with the ODS reaction, near complete removal can be achieved on a relatively short timescale. (b) Recycling experiments using $\mathrm{MoO}_{2} @$ GNF with no catalyst treatment between runs for the ODS of DBT indicated a $\sim 40 \%$ lower sulphur removal capacity after the first use, with no significant changes noted over the next four uses. Analysis of the used catalyst by PXRD (c) indicated the selective retention of the products of ODS (* sulfoxide, \# sulfone, $\bullet$ catalyst) within the nanoreactor cavity after the initial use. This was confirmed by TGA (d), with a mass loss at $242{ }^{\circ} \mathrm{C}$ (i), prior to $\mathrm{GNF}$ combustion at $589{ }^{\circ} \mathrm{C}$ (ii), consistent the boiling point of $\mathrm{DBTO}_{2}$. The presence of the products of ODS within GNF after the first use provides strong evidence for the ability of $\mathrm{MoO}_{2} @$ GNF to decontaminate model fuels using a dual functional approach, i.e. involving both ODS of DBT and ADS of the ODS reaction products. Moreover, the 


\section{WILEY-VCH}

retention of activity use-to-use after the initial drop, in the absence of an intermediate catalyst washing step, indicates that the products of the ODS reactions do not permanently block the GNF nanoreactor cavity and therefore access of DBT molecules to the catalyst in subsequent uses is not restricted. Thus, the observed reduction in sulphur removal after the initial use reflects the slower accumulation of DBT molecules at the GNF step-edges, requiring initial desorption of the ODS products from the cavity of the used $\mathrm{MoO}_{2} @ \mathrm{GNF}$ catalyst into the fresh model fuel, i.e. down a $\mathrm{DBTO}_{2}$ concentration gradient, to provide a route for access of new DBT reactant molecules to the catalytic centres. The introduction of either a $250{ }^{\circ} \mathrm{C}$ thermal treatment or washing with a polar solvent between consecutive ODS reactions effectively removes these products from the channel and is essential for ensuring high catalytic activity even after five uses (b). A very small drop in catalyst performance is still noted between uses one to five and this has been attributed to subtle changes in nanoparticle morphology and loading induced during successive reactions.

a)

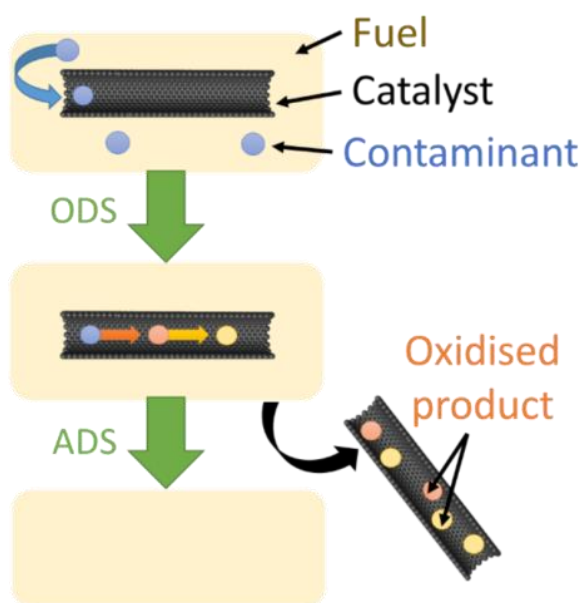

b)

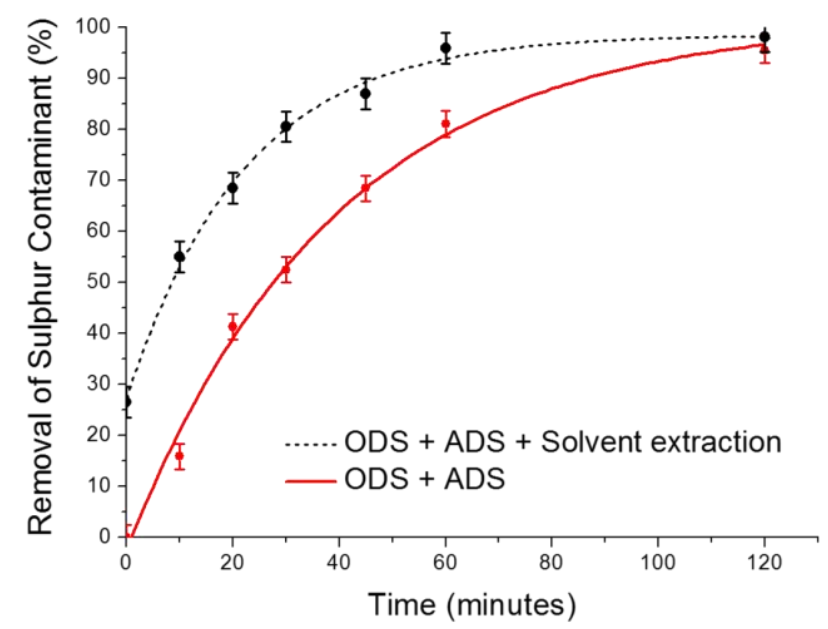

Figure 7. (a) Schematic diagram describing the process of oxidation and extraction using the nanoreactor and nanosponge composite material to achieve effective removal of sulphur contaminants. (b) Kinetic profile for the removal of DBT from an $n$-hexane model fuel using the ODS procedure alone ( $5 \mathrm{mg} \mathrm{MoO}_{2} @ \mathrm{GNF}, 5 \mathrm{ml}$ fuel, 1:20 S:O ratio, $60{ }^{\circ} \mathrm{C}$ ), thus exploiting the nanosponge potential for extraction. These results show that there is a near 
linear removal of DBT up to 60 mins. After 120 mins, near complete removal can be achieved without the need for a separate solvent extraction.

Table 1. Dibenzothiophene removal from the model fuel system.

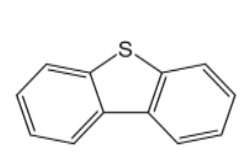

Dibenzothiophene (DBT)

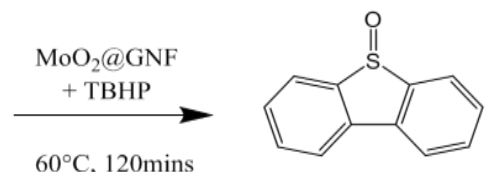

Dibenzothiophene sulfoxide (DBTO)

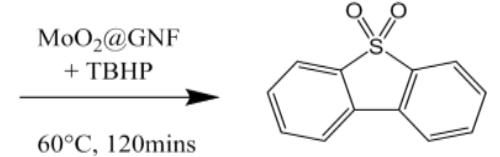

Dibenzothiophene sulfone $(\mathrm{DBTO})$

\begin{tabular}{|c|c|c|c|c|c|c|}
\hline Entry & Catalyst a & $\begin{array}{c}\text { Sulphur } \\
\text { removal with } \\
\text { ODS } \\
\text { procedure only } \\
(\%)^{b}\end{array}$ & $\begin{array}{c}\text { Sulphur } \\
\text { removal } \\
\text { with ODS } \\
\text { and } \\
\text { solvent } \\
\text { extraction } \\
(\%)^{b}\end{array}$ & $\begin{array}{c}\text { DBT } \\
\text { conversion } \\
(\%)^{c}\end{array}$ & $\begin{array}{l}\text { Selectivity (\%) } \\
\text { DBTO : DBTO2 }\end{array}$ & $\begin{array}{c}\text { Turnover } \\
\text { frequency } \\
\left(\mathrm{mol} \mathrm{mol}^{-1} \mathrm{mi}\right. \\
\left.\mathbf{1}^{\mathrm{d}}\right)^{d}\end{array}$ \\
\hline 1 & None & 0.0 & $28.8(29.4)$ & 0.0 & $-:-$ & - \\
\hline 2 & GNF & 0.0 & $28.6(30.1)$ & 0.0 & $-:-$ & - \\
\hline 3 & $\mathrm{MoO}_{2} @ \mathrm{GNF}$ & 95.5 & 98.8 (98.1) & 96.8 & $14: 86$ & $0.14(0.45)$ \\
\hline 4 & $\mathrm{MoO}_{3} @ \mathrm{GNF}$ & 46.3 & $72.7(75.1)$ & 57.2 & $76: 24$ & 0.08 \\
\hline 5 & $\mathrm{MoO}_{2} @$ Graphite & 44.4 & $71.5(74.2)$ & 60.8 & $75: 25$ & 0.09 \\
\hline
\end{tabular}

a) $5 \mathrm{mg}$ catalyst (containing 4 wt. $\% \mathrm{MoO}_{\mathrm{x}}$ ), $5 \mathrm{ml}$ of $n$-hexane containing $500 \mathrm{ppm}$ DBT, tertbutylhydroperoxide (TBHP) oxidant ( $\mathrm{S}: \mathrm{O}$ is $1: 20), 60{ }^{\circ} \mathrm{C}, 120$ mins.; ${ }^{\text {b) }}$ Percentage of sulphurcontaining contaminants removed via either (i) ODS or (ii) combined ODS and solvent extraction (1 $\mathrm{ml} \mathrm{CD} \mathrm{C}_{3} \mathrm{CN}, 30$ mins) was determined using UV-Vis spectroscopy and GC-MS (GC-MS values shown in parentheses); ${ }^{c}$ The conversion of DBT and selectivity of products was calculated using GC-MS of fuel phase and ${ }^{1} \mathrm{H}$ NMR spectroscopy of solvent extraction phase and a solvent washing of postreaction solid catalysts; ${ }^{\text {d) }}$ Turnover frequency calculated from the conversion of $4 \%$ weight loaded $\mathrm{MoO}_{\mathrm{x}}$ nanomaterials with 120 mins ODS experiment (the value in parenthesis describes the value determined using the conversion obtained after only 30 mins). 
WILEY-VCH

Table 2. Dibenzothiophene removal from the model fuel system.

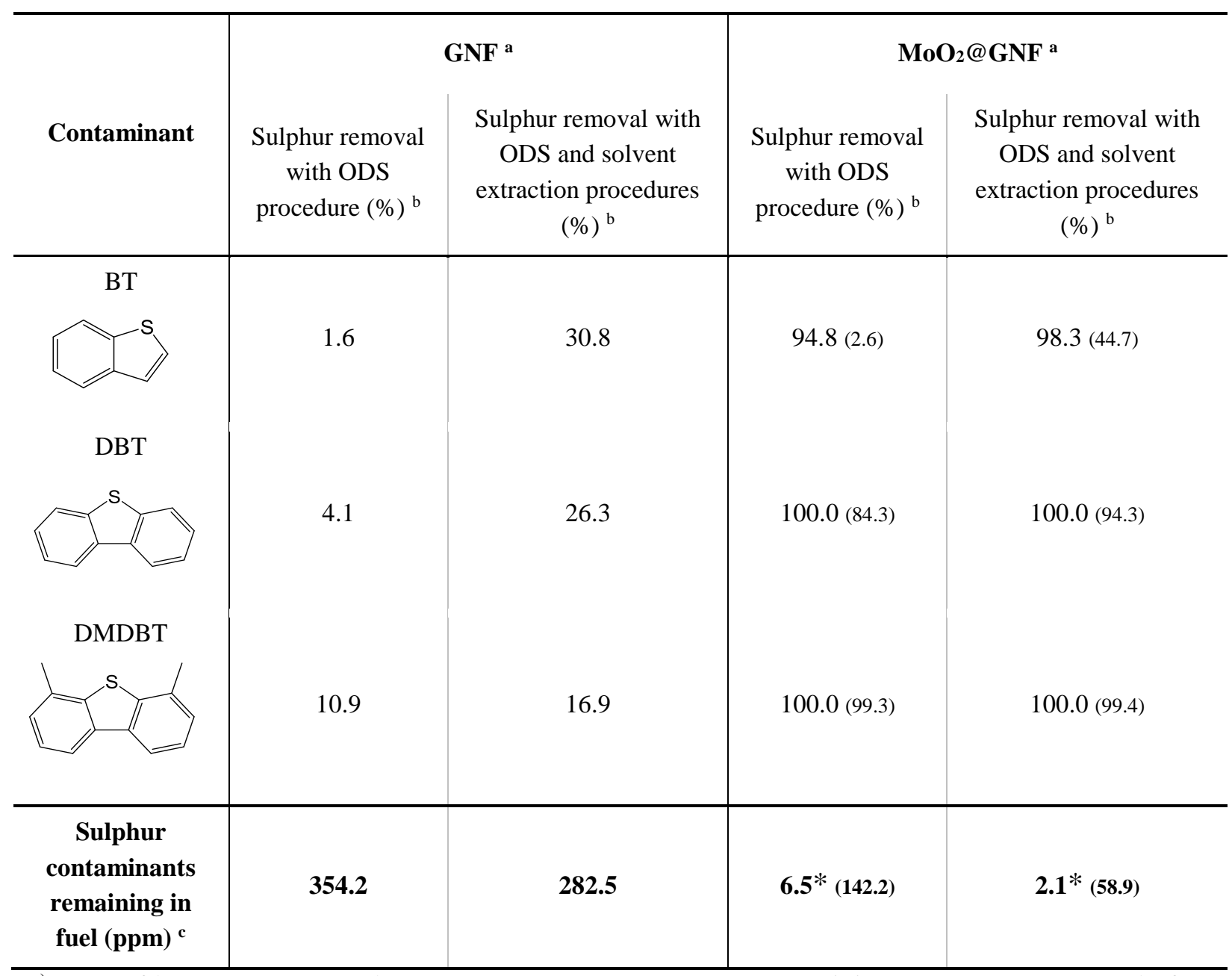

a) $5 \mathrm{mg}$ of heterogeneous catalyst (empty GNF or $\mathrm{MoO}_{2} @ \mathrm{GNF}$ containing $4 \mathrm{wt} . \% \mathrm{MoO}_{\mathrm{x}}$ ), $5 \mathrm{ml}$ of $n$ octane containing three contaminants (125 ppm of benzothiophene - BT, dibenzothiophene - DBT and dimethyldibenzothiophene - DMDBT), sulphur:oxidant molar ratio is $1: 20$, tertbutylhydroperoxide oxidant, $60{ }^{\circ} \mathrm{C}, 18 \mathrm{hrs}$ (values in parentheses correspond to data collected after 2 hrs); ${ }^{b)}$ Percentage of sulphur-containing contaminants removed via either (i) ODS or (ii) combined ODS and solvent extraction ( $\left.1 \mathrm{ml} \mathrm{CD}_{3} \mathrm{CN}, 30 \mathrm{mins}\right)$ was determined using GC-MS; ${ }^{c}$ Sum of contaminants removed from the fuel in ppm. * Represent values below those required by current regulations. 


\section{WILEY-VCH}

The table of contents entry should be 50-60 words long, and the first phrase should be bold. The entry should be written in the present tense and impersonal style. The text should be different from the abstract text.

The principle of a 'catalytic nanosponge' that combines the catalysis of organosulphur oxidation and sequestration of the products simultaneously for the effective desulphurisation of liquid fuel has been demonstrated. Carbon nanoreactors are utilised to enhance the activity and durability of encapsulated molybdenum dioxide nanoparticles, leading to recyclable catalytic nanosponges which are able to decontaminate to ultra-low sulphur fuel requirements.

Keywords; oxidative desulphurisation, nanoreactors, nanosponges, carbon nanotubes, molybdenum dioxide

M. A. Astle, G. A. Rance, H. J. Loughlin, T. D. Peters, A. N. Khlobystov*

Molybdenum Dioxide in Carbon Nanoreactors as a Catalytic Nanosponge for Efficient Desulphurisation of Liquid Fuels

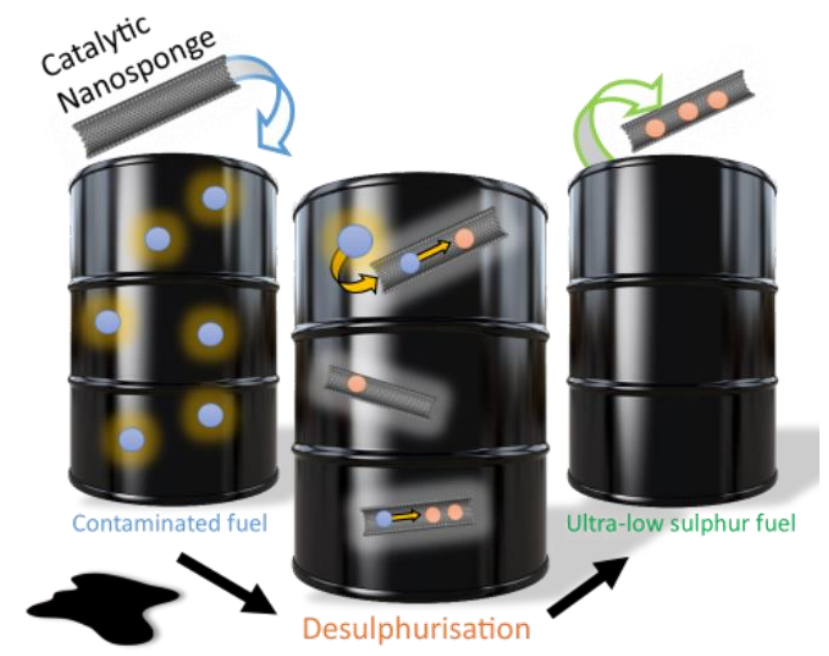

ToC figure 


\section{WILEY-VCH}

Copyright WILEY-VCH Verlag GmbH \& Co. KGaA, 69469 Weinheim, Germany, 2016.

\section{Supporting Information}

Molybdenum Dioxide in Carbon Nanoreactors as a Catalytic Nanosponge for the Efficient Desulphurisation of Liquid Fuels

Maxwell A. Astle, Graham A. Rance, Hannah Loughlin, Thomas D. Peters, and Andrei N. Khlobystov*

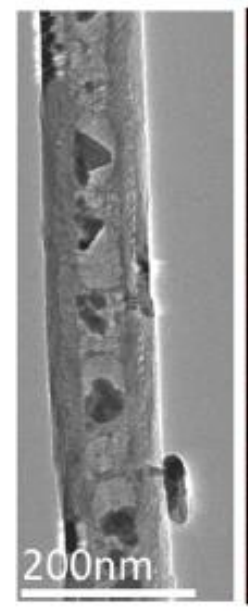

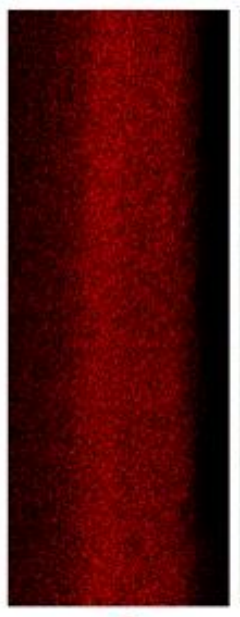

a

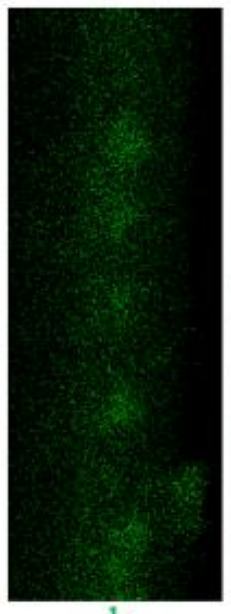

b

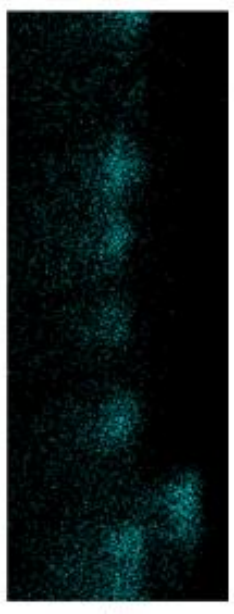

Figure S1 - Bright field TEM image and EDX elemental mapping of (a) carbon, (b) oxygen and (c) molybdenum in $\mathrm{MoO}_{2} @ \mathrm{GNF}$, confirming the co-location of oxygen and molybdenum in the nanoparticles, consistent with the formation of metal oxide. 


\section{WILEY-VCH}
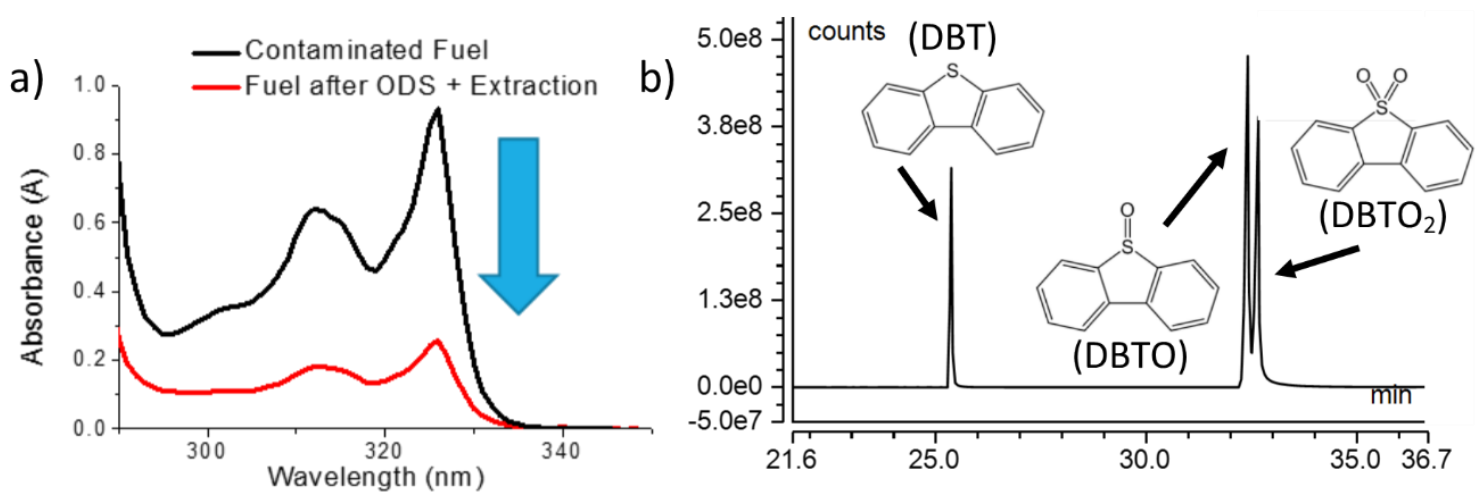

Figure S2 - (a) UV-Vis spectra of the DBT model fuel system before and after the ODS procedure.

The peak at $326 \mathrm{~nm}$ corresponds to the $\pi-\pi^{*}$ transition in the aromatic ring of DBT and can be used to quantify the removal of DBT from the model fuel. (b) Representative GC-MS analysis of the fuel phase without solvent extraction.

Table S1 - Sulphur removal of fuel using different loadings of $\mathrm{MoO}_{2} @$ GNF after a 30 minutes ODS procedure.

\begin{tabular}{|c|c|c|c|c|c|c|}
\hline Entry & $\begin{array}{c}\text { Quantity of } \\
\mathrm{MoO}_{2} @ \text { GNF } \\
(\mathbf{m g})^{\text {a, b }}\end{array}$ & $\begin{array}{c}\text { Sulphur } \\
\text { removal } \\
\text { with ODS } \\
\text { procedure } \\
\qquad \%)^{c}\end{array}$ & $\begin{array}{c}\text { Sulphur } \\
\text { removal with } \\
\text { ODS and } \\
\text { solvent } \\
\text { extraction } \\
\text { procedures }^{\text {ond }} \\
(\%)^{c}\end{array}$ & $\begin{array}{c}\text { Conversion } \\
(\%)^{\mathrm{d}}\end{array}$ & $\begin{array}{c}\text { Selectivity (\%) } \\
\text { d } \\
\text { DBTO :DBTO }\end{array}$ & $\begin{array}{c}\text { Turnover } \\
\text { frequency } \\
\left(\mathrm{mol} \mathrm{mol}^{-1}\right. \\
\left.\min ^{-1}\right)^{\mathrm{e}}\end{array}$ \\
\hline 1 & 1 & 30.6 & 57.3 & 43.6 & $83: 17$ & 1.22 \\
\hline 2 & 2.5 & 39.7 & 66.3 & 54.0 & $71: 28$ & 0.61 \\
\hline 3 & 5 & 52.5 & 76.7 & 67.8 & $69: 31$ & 0.43 \\
\hline \multicolumn{7}{|c|}{$\begin{array}{l}{ }^{\text {a }} \text { catalyst containing } 4 \mathrm{wt} \% \mathrm{MoO}_{\mathrm{x}}{ }^{\mathrm{b}} 5 \mathrm{ml} \text { of } n \text {-hexane containing } 500 \mathrm{ppm} \text { DBT, sulphur:oxidant } \\
\text { molar ratio is } 1: 20 \text {, tert-butylhydroperoxide oxidant, } 60{ }^{\circ} \mathrm{C}, 30 \mathrm{mins} .{ }^{\mathrm{c}} \text { Percentage of sulphur- } \\
\text { containing contaminants removed via either (i) ODS or (ii) combined ODS and solvent extraction }(1 \mathrm{ml} \\
\mathrm{CD}_{3} \mathrm{CN}, 30 \text { mins) was determined using UV-Vis spectroscopy. }{ }^{\mathrm{d}} \text { The conversion of DBT and } \\
\text { selectivity of products was calculated using sulphur removal of the fuel phase and }{ }^{1} \mathrm{H} \mathrm{NMR} \\
\text { spectroscopy analysis of the combined solvent extraction phase and the washings of the post-reaction } \\
\text { solid catalysts. }{ }^{\mathrm{e}} \text { Turnover frequency calculated from conversion of } 4 \% \text { weight loaded } \mathrm{MoO}_{x} \\
\text { nanomaterials at } 30 \text { mins. }\end{array}$} \\
\hline
\end{tabular}




\section{WILEY-VCH}

Table S2 - Adsorption experiments probing the uptake of DBT by $\mathrm{MnO}_{2} @ \mathrm{GNF}$. For these experiments, 500 ppm DBT in $n$-hexane was added to $5 \mathrm{mg}$ of $\mathrm{MnO}_{2} @ \mathrm{GNF}$, the mixture stirred at room temperature for $60 \mathrm{mins}$, the catalyst removed by filtration and the UV-vis spectrum recorded. The experiment was performed in triplicate and the mean DBT concentration determined using the absorbance at $326 \mathrm{~nm}\left(\varepsilon=3100 \mathrm{dm}^{3} \mathrm{~mol}^{-1} \mathrm{~cm}^{-1}\right)$, subsequently converted into ppm (entry 2). A control measurement in the absence of a catalyst was also performed (entry 1). These measurements indicate that there is a small, but measurable, decrease in the DBT concentration in the presence of $\mathrm{MoO}_{2} @ \mathrm{GNF}$, relative to the absence of the catalyst and marginally above the standard deviation of multiple measurements (1 ppm), consistent with the selective adsorption of DBT by GNF through an ADS mechanism. However, the extremely low uptake value precludes the sole application of ADS of DBT for effective desulphurisation of model fuels and highlights the importance of combined ODS of DBT and ADS of the products of DBT oxidation utilised in this study for fuel desulphurisation.

\begin{tabular}{ccc}
\hline Entry & Catalyst & DBT concentration / ppm \\
\hline 1 & - & 500 \\
2 & $\mathrm{MoO}_{2} @ \mathrm{GNF}$ & 495 \\
\hline
\end{tabular}




\section{WILEY-VCH}

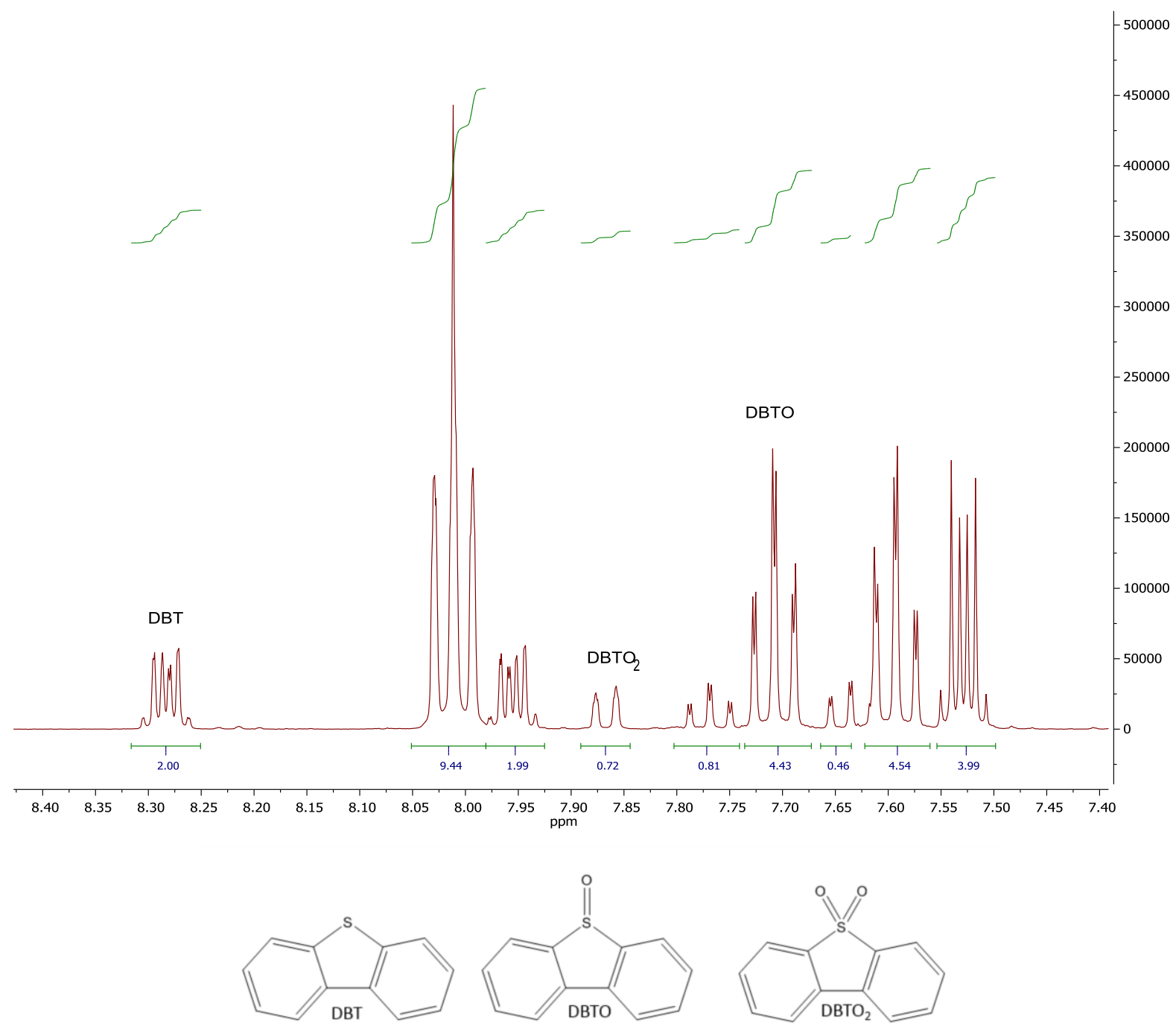

Figure S3 - Representative ${ }^{1} \mathrm{H}$ NMR spectrum obtained from an intermediate stage reaction mixture of typical ODS and solvent extraction procedures of DBT with $\mathrm{MoO}_{2} @ \mathrm{GNF}$ nanoreactors $(5 \mathrm{mg}$ $\mathrm{MoO}_{2} @ \mathrm{GNF}, 5 \mathrm{ml}$ fuel, 1:20 S:O ratio, $60{ }^{\circ} \mathrm{C}, 20$ mins with solvent extraction 5:1 hexane: acetonitrile, 30 mins). Environments used for calculation of the DBT conversion and selectivity for the two oxidised products are identified. 


\section{WILEY-VCH}
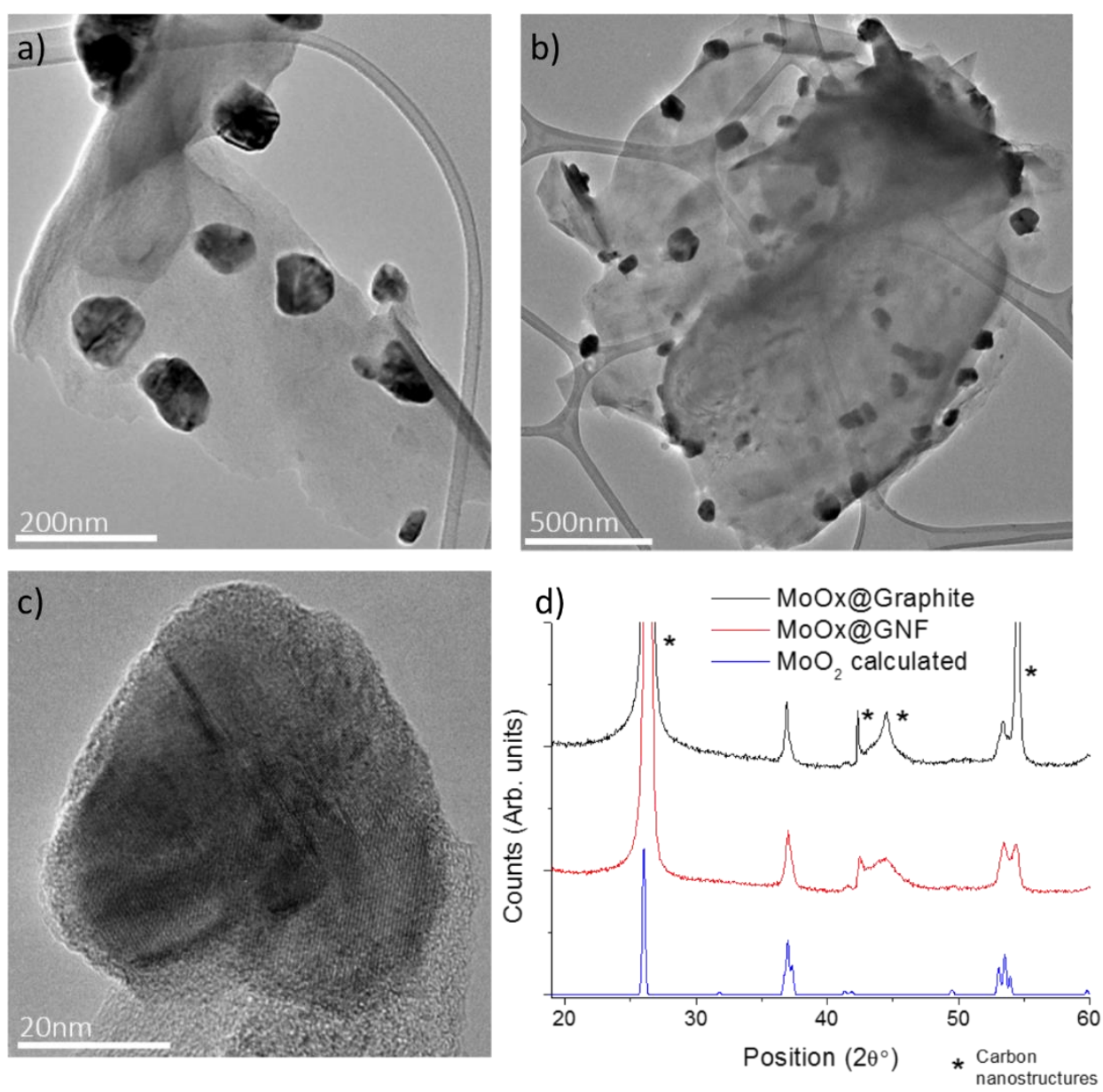

Figure S4 - (a), (b) and (c) TEM of $\mathrm{MoO}_{2} @$ graphite confirming formation of composite materials with (d) PXRD confirming the presence of larger $\mathrm{MoO}_{2}$ nanoparticles formed. 


\section{WILEY-VCH}
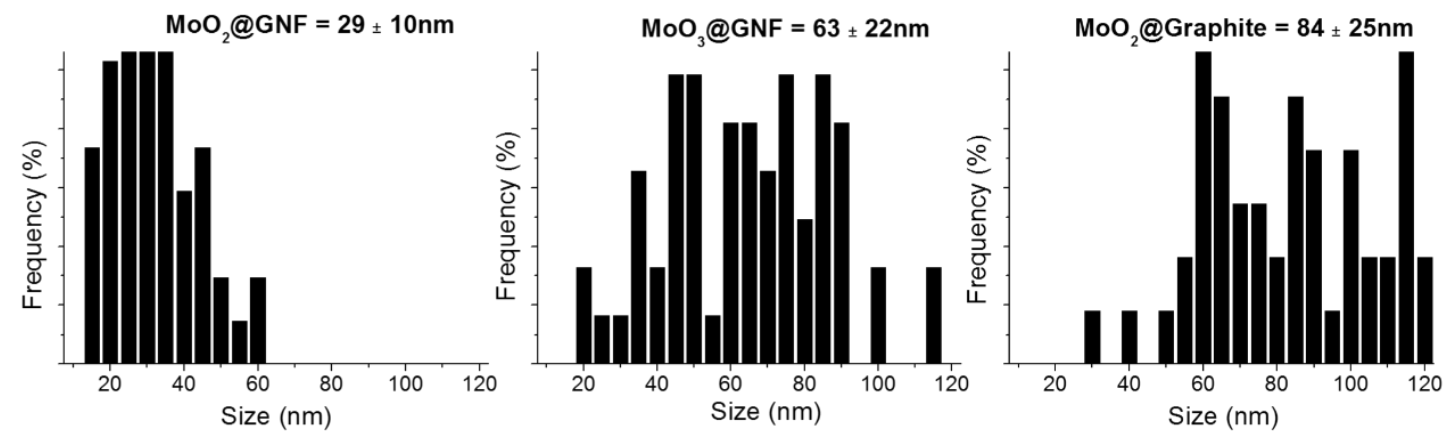

Figure S5 - Nanoparticle size distributions for the composite materials. $\mathrm{MoO}_{3}$ has been shown to be an effective ODS catalyst; however, the $\mathrm{MoO}_{3} @$ GNF nanoreactor generated by post-synthesis thermal treatment removes comparatively lower amounts of the sulphur contaminant relative to $\mathrm{MoO}_{2} @ \mathrm{GNF}$ (Table 1 - entries 3 and 4). Although the difference in oxidation state is likely to impact catalyst performance, TEM analysis revealed an increase in nanoparticle size and therefore the observed decrease in ODS activity could be a result of a reduction in the surface area of the catalyst. However, in $\mathrm{MoO}_{2} @$ graphite, the nanoparticles are even larger but yield similar levels of sulphur removal, thus suggesting that surface area may not be a major contributor in this system.
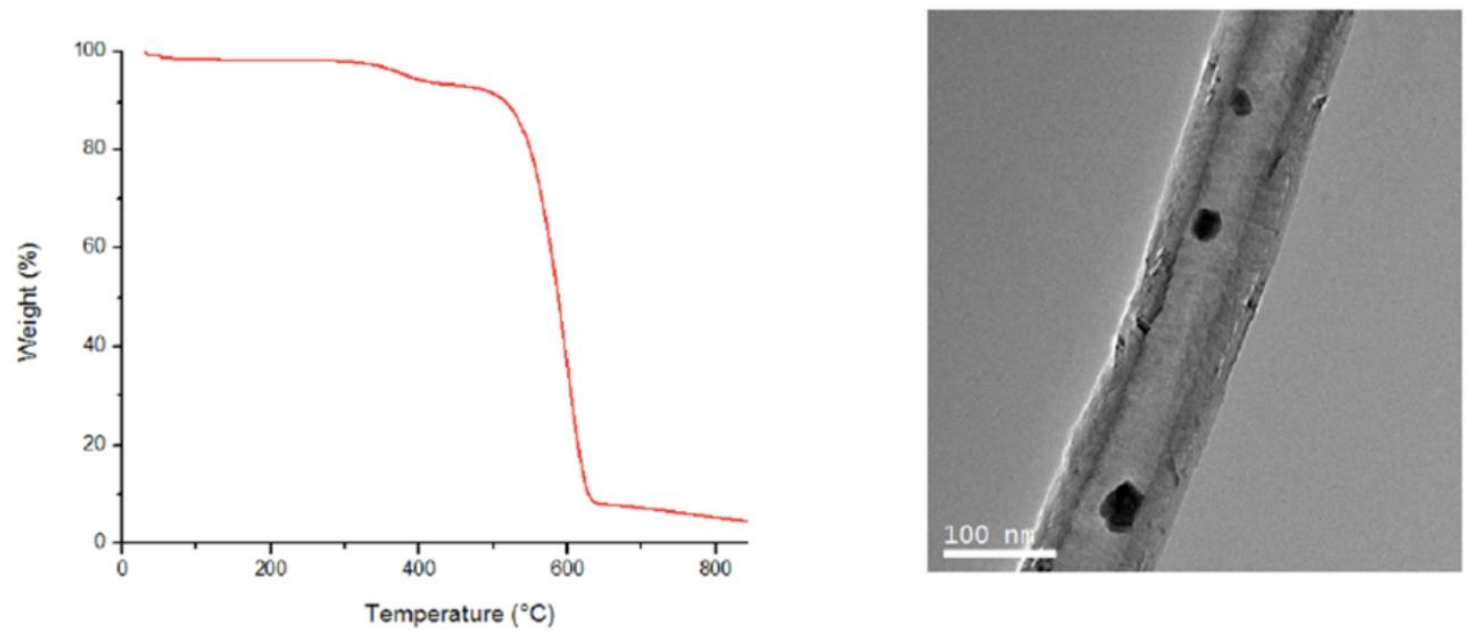

Figure S6 - TGA and TEM of the catalyst recycled after three cycles of the ODS procedure. The residual weight from TGA is shown to be $3.8 \%$ indicating a small (within error) loss in weight relative to the metal loading in the parent catalyst; however, there remains a notable reduction in the GNF combustion temperature indicative of the retention of $\mathrm{MoO}_{\mathrm{x}}$ species. TEM is able to confirm the presence of the encapsulated species retained. 


\section{WILEY-VCH}

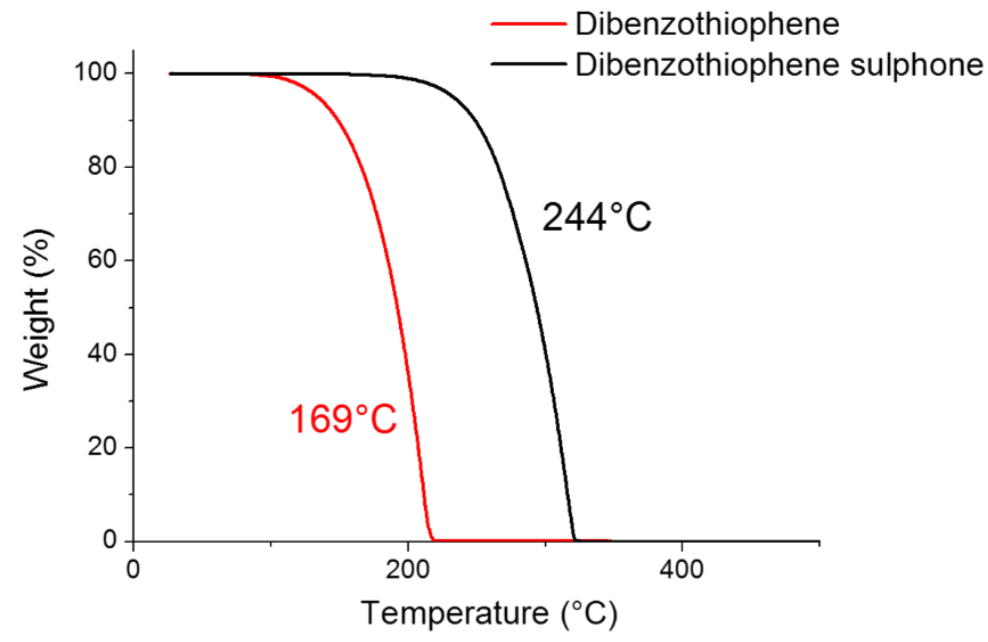

Figure S7 - TGA of the starting material (DBT) and its doubly oxidised product $\left(\mathrm{DBTO}_{2}\right)$.

\section{Solvent extraction combined with catalyst washing}

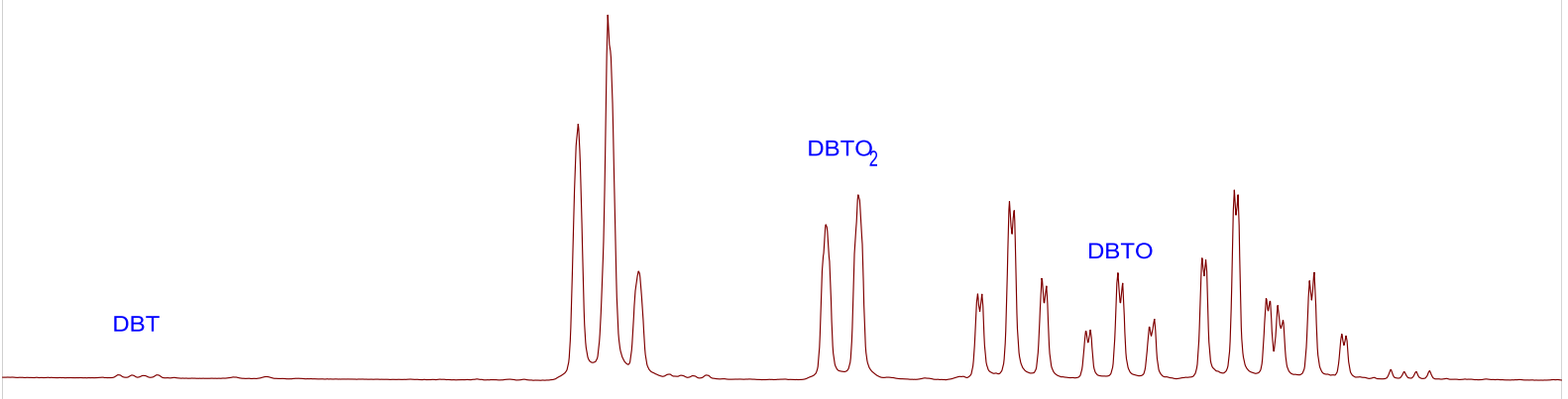

\section{Solvent extraction only}

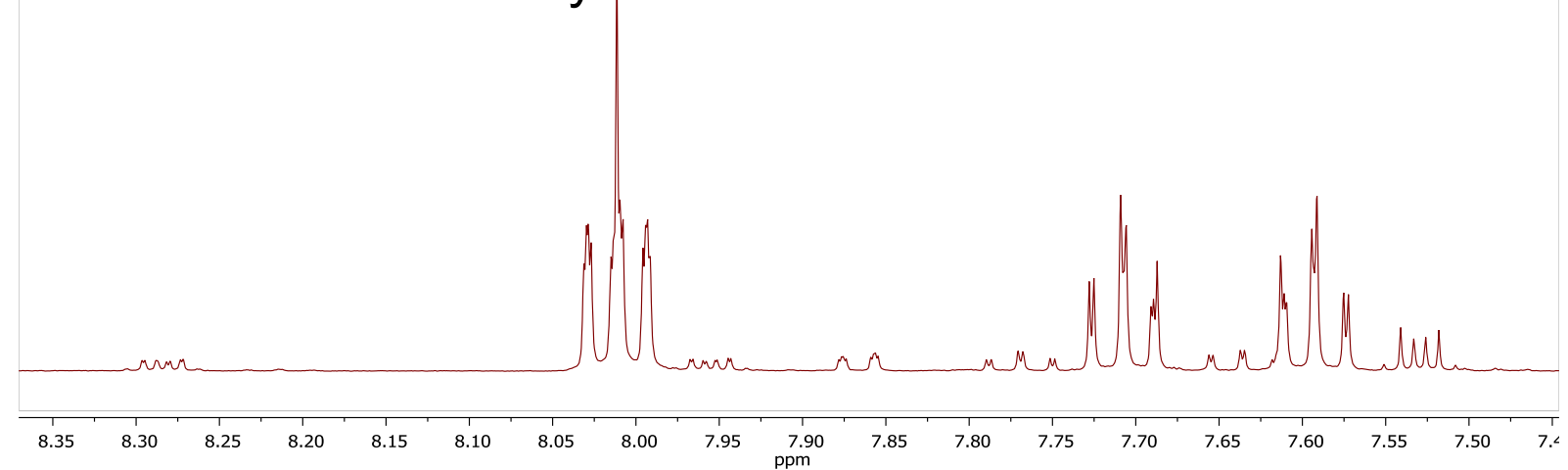

Figure S8 $-{ }^{1} \mathrm{H}$ NMR spectra of solvent extraction product showing minimal DBT removed by solvent extraction alone, whereas the oxidised products more effectively removed. Combining this with a catalyst washing step indicates that the oxidised products are retained by the catalyst and permits more accurate evaluation of DBT conversion for each reaction. 


\section{WILEY-VCH}

Table S3 - Comparison of the various catalysts used for oxidative desulphurisation of DBT in model fuels.

\begin{tabular}{|c|c|c|c|c|c|c|c|}
\hline Catalyst & $\begin{array}{c}\text { Weight of } \\
\text { Contaminant } \\
\text { : catalyst } \\
\left(\mathrm{mol} \mathrm{g}^{-1}\right)^{\mathrm{a}}\end{array}$ & $\begin{array}{c}\text { Reaction } \\
\text { time } \\
\text { (min) }\end{array}$ & $\begin{array}{c}\text { DBT } \\
\text { removal } \\
(\%)\end{array}$ & $\begin{array}{l}O: S \\
\text { ratio }\end{array}$ & $\mathrm{T}\left({ }^{\mathrm{O}} \mathrm{C}\right)$ & $\begin{array}{l}\text { Desulphurisation } \\
\text { factor } \\
\left(\mathbf{m o l ~ g}^{-1} \mathbf{m i n}^{-1}\right)^{b}\end{array}$ & Ref \\
\hline HPMo/BN-IL & 0.0016 & 100 & 94.3 & 4 & 40 & $1.48 \times 10^{-5}$ & [41] \\
\hline $\mathrm{Ce}_{2} \mathrm{Mo}_{10} \mathrm{~W}_{2} / \mathrm{SBA}$ & 0.0040 & 80 & 100.0 & 5 & 60 & $4.92 \times 10^{-5}$ & [39] \\
\hline $\mathrm{MoO}_{3} / \mathrm{Al}_{2} \mathrm{O}_{3}$ & 0.00056 & 30 & 90.5 & 3 & 60 & $1.70 \times 10^{-5}$ & [21] \\
\hline $\begin{array}{l}\mathrm{Cs}_{2} \mathrm{H}\left[\mathrm{PW}_{4} \mathrm{Mo}_{8} \mathrm{O}_{40}\right] \\
\text { on Iron Oxide @ } \\
\text { Mesoporous Silica }\end{array}$ & 0.023 & 60 & 94.0 & 17 & 60 & $3.54 \times 10^{-4}$ & [42] \\
\hline $\mathrm{MoO}_{2} @ \mathrm{GNF}$ & 0.39 & 120 & 98.8 & 20 & 60 & $3.13 \times 10^{-3}$ & This work \\
\hline $\mathrm{MoO}_{2} @ \mathrm{GNF}$ & 0.20 & 120 & 89.0 & 5 & 60 & $1.46 \times 10^{-3}$ & This Work \\
\hline \multicolumn{8}{|c|}{$\begin{array}{l}\text { a The contaminant weight }(\mathrm{mol}) \text { per active catalyst weight }(\mathrm{g}) \text { in each oxidative desulphurisation } \\
\text { reaction. }{ }^{\mathrm{b}} \text { Calculated using the percentage of contaminant removal per weight percent of contaminant } \\
\text { to catalysts loading per unit time. Example calculation for desulphurisation factor: moles of sulphur } \\
\text { contaminant in each ODS reaction divided by the active catalyst loading without support in grams. } \\
\text { This value is multiplied by percentage removal/100 and divided by the reaction time to give a term } \\
\text { similar to turn over frequency called "desulphurisation factor" which allows normalisation of all } \\
\text { literature data and effective comparisons of each catalyst. }\end{array}$} \\
\hline
\end{tabular}




\section{WILEY-VCH}

Table S4 - The effect of solvent on the ODS of DBT. These results show insignificant difference between $n$-hexane and $n$-octane when employed as the solvent in the model fuel.

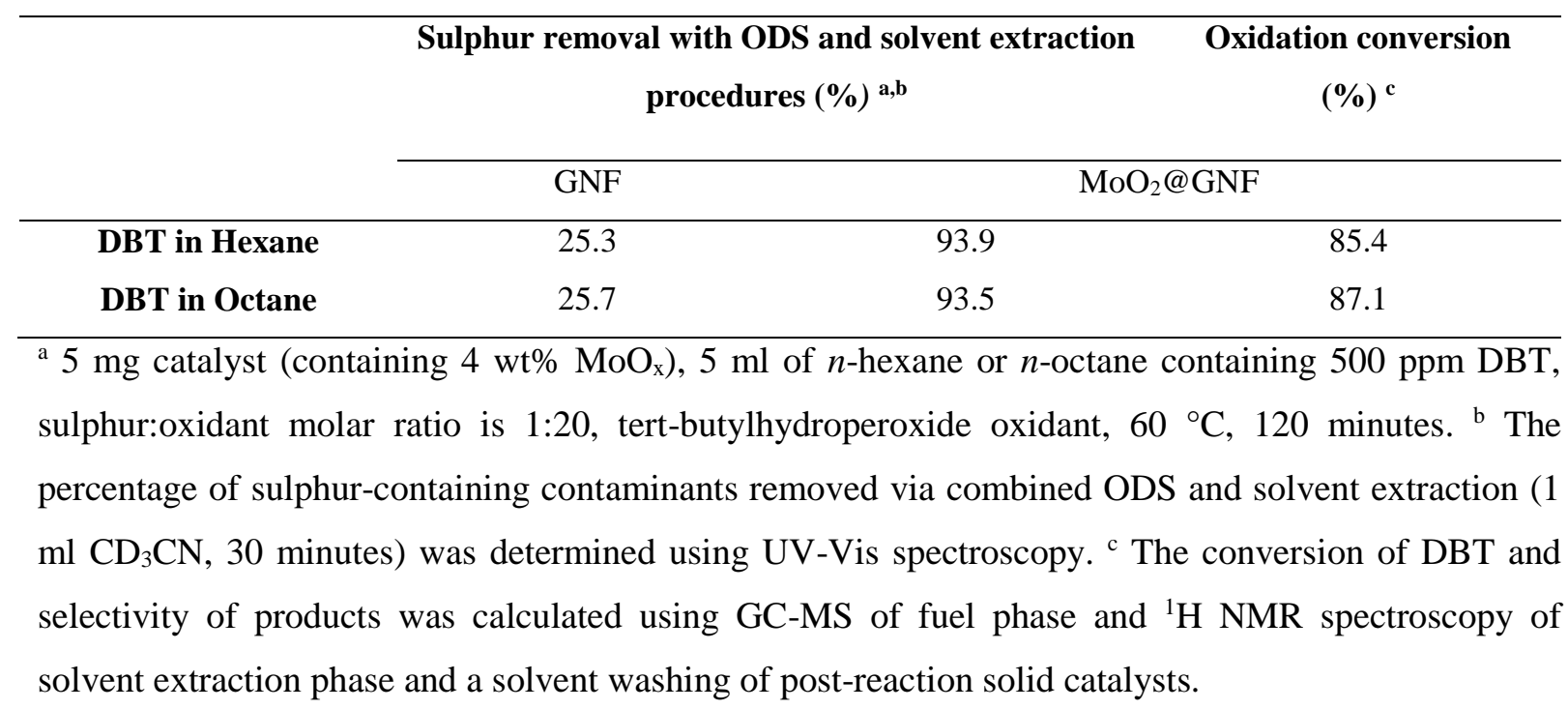

Table S5 - Oxidation conversion values for mixed fuel system with $\mathrm{MoO}_{2} @ \mathrm{GNF}$.

\begin{tabular}{ccc}
\hline & $\begin{array}{c}\text { Contaminant conversion } \\
\text { using GNF (\%) }\end{array}$ & $\begin{array}{c}\text { Contaminant conversion using } \\
\mathbf{M o O}_{2} @ \mathbf{G N F}(\boldsymbol{\%})^{\mathbf{a}, \mathbf{b}}\end{array}$ \\
BT & 0.0 & $95.3(9.1)$ \\
DBT & 0.0 & $95.7(86.8)$ \\
DMDBT & 0.0 & $94.8(91.7)$ \\
\hline
\end{tabular}

$\overline{{ }^{a}} 5 \mathrm{ml}$ of $n$-octane containing three contaminants (125 ppm of benzothiophene - BT, dibenzothiophene

- DBT and dimethyldibenzothiophene - DMDBT), sulphur:oxidant molar ratio is 1:20, tertbutylhydroperoxide oxidant, $60{ }^{\circ} \mathrm{C}, 18 \mathrm{hr}$ ( $2 \mathrm{hr}$ values in parentheses). The conversion of contaminants was calculated using GC-MS analysis of the fuel phase and ${ }^{1} \mathrm{H}$ NMR spectroscopy of the solvent extraction phase and a solvent washing of post-reaction solid catalysts. ${ }^{\mathrm{b}} 5 \mathrm{mg}$ catalyst (containing 4 $\mathrm{wt} \% \mathrm{MoO}_{\mathrm{x}}$ ). 